\title{
Universiteit
}

Leiden

The Netherlands

\section{Effects of fatty acids on $T$ cell function: role in atherosclerosis}

Reilly, N.A.; Lutgens, E.; Kuiper, J.; Heijmans, B.T.; Jukema, J.W.

\section{Citation}

Reilly, N. A., Lutgens, E., Kuiper, J., Heijmans, B. T., \& Jukema, J. W. (2021). Effects of fatty acids on T cell function: role in atherosclerosis. Nature Reviews Cardiology.

doi:10.1038/s41569-021-00582-9

Version: $\quad$ Publisher's Version

License: $\quad$ Licensed under Article 25fa Copyright Act/Law (Amendment Taverne)

Downloaded from: https://hdl.handle.net/1887/3216819

Note: To cite this publication please use the final published version (if applicable). 


\title{
REVIEWS
}

Check for updates

\section{Effects of fatty acids on $\mathrm{T}$ cell function: role in atherosclerosis}

\author{
Nathalie A. Reilly $\mathbb{1}^{1,2}$, Esther Lutgens ${ }^{3,4,5}$, Johan Kuiper $\mathbb{1}^{6}$, Bastiaan T. Heijmans $\mathbb{1}^{1,8}$ \\ and J. Wouter Jukema $\mathbb{D}^{2,7,8 凶}$
}

Abstract $\mid T$ cells are among the most common cell types present in atherosclerotic plaques and are increasingly being recognized as a central mediator in atherosclerosis development and progression. At the same time, triglycerides and fatty acids have re-emerged as crucial risk factors for atherosclerosis. Triglycerides and fatty acids are important components of the milieu to which the T cell is exposed from the circulation to the plaque, and increasing evidence shows that fatty acids influence T cell function. In this Review, we discuss the effects of fatty acids on four components of the T cell response - metabolism, activation, proliferation and polarization and the influence of these changes on the pathogenesis of atherosclerosis. We also discuss how quiescent $T$ cells can undergo a type of metabolic reprogramming induced by exposure to fatty acids in the circulation that influences the subsequent functions of T cells after activation, such as in atherosclerotic plaques.

Thelper 1 cells ( $T_{H} 1$ cells). A subtype of $\mathrm{CD}^{+}$ T cell characterized by the expression of the transcription factor T-bet and the production of pro-inflammatory cytokines, such as IFN $\mathrm{IL}$, -2 and TNF $\mathrm{T}_{\mathrm{H}} 1$ cells have been shown to be pro-atherogenic.

$\mathrm{T}_{\mathrm{H}} 2$ cells

A subtype of $C D 4^{+} T$ cell

characterized by the expression of the transcription factor GATA3 and the production of anti-inflammatory cytokines, such as IL-4, IL-5 and IL-13. The role of $\mathrm{T}_{\mathrm{H}} 2$ cells in atherosclerosis is not completely clear, although anti-atherogenic properties have been described.

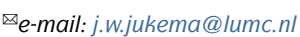
https://doi.org/10.1038 s41569-021-00582-9
Atherosclerosis is the primary underlying cause of cardiovascular disease (CVD) and is characterized by interactions among lipids, the immune system and the vascular wall ${ }^{1}$. The hallmark of atherosclerosis is lipid accumulation in the arterial intima ${ }^{1}$. Both LDL, laden with cholesterol, and innate immune cells, specifically monocytes and macrophages, have crucial roles in the development of atherosclerosis ${ }^{2-5}$. However, it is increasingly clear that these factors cannot account for the full pathological mechanisms of atherosclerosis.

Atherosclerotic plaques have long been known to contain an adaptive immune component. T cells are an important part of the adaptive immune response and were originally thought to comprise $10 \%$ of all cells in the atherosclerotic plaque ${ }^{6,7}$. The functions of $\mathrm{T}$ cells and their major subsets, $\mathrm{CD} 4^{+} \mathrm{T}$ cells and $\mathrm{CD} 8^{+}$cytotoxic $\mathrm{T}$ cell, have been extensively studied in this context. $\mathrm{CD}^{+} \mathrm{T}$ cells are the most prominent $\mathrm{T}$ cell subtype in atherosclerosis and generally contribute to the development of disease, as observed in studies showing that adoptive transfer of $\mathrm{CD}^{+} \mathrm{T}$ cells aggravates the atherosclerosis in immunodeficient $A p o e^{-/-}$mice $^{8-12}$. CD $4^{+}$ $\mathrm{T}$ cells can be further subdivided into $\mathrm{T}$ helper 1 cells ( $T_{H} 1$ cells), $T_{H} 2$ cells, $T_{H} 17$ cells and regulatory $T$ cells ( $\mathrm{T}_{\text {reg }}$ cells) ( $\mathrm{BOX} 1$ ). $\mathrm{T}_{\mathrm{H}} 1$ cells seem to be the predominant $\mathrm{T}$ cell subset in atherosclerotic plaques and the most pro-atherogenic subset, whereas $\mathrm{T}_{\text {reg }}$ cells have anti-atherogenic functions ${ }^{11,12}$. The exact roles of $\mathrm{T}_{\mathrm{H}} 2$ cells, $\mathrm{T}_{\mathrm{H}} 17$ cells and $\mathrm{CD} 8^{+} \mathrm{T}$ cells remain unclear because both pro-atherogenic and anti-atherogenic effects have been reported ${ }^{10-16}$. Although the total number of $\mathrm{CD} 8^{+}$
T cells is low in early atherosclerotic lesions, the number increases as the disease progresses ${ }^{10-13}$.

As techniques to study atherosclerosis have progressed, the importance of $\mathrm{T}$ cells in atherosclerosis development and progression has become increasingly clear. A study using optical coherence tomography with simultaneous immunophenotyping by flow cytometry analysis of the culprit atherosclerotic lesion in patients with an acute coronary syndrome showed enrichment of both $\mathrm{CD}^{+} \mathrm{T}$ cells and $\mathrm{CD} 8^{+} \mathrm{T}$ cells in plaques with intact fibrous caps compared with ruptured plaques ${ }^{17}$. Studies using single-cell RNA sequencing showed that $\mathrm{T}$ cells make up about half of the $\mathrm{CD} 45^{+}$leukocytes present in atherosclerotic plaques in both humans and mice $^{18-20}$. Furthermore, analyses with other techniques, such as mass cytometry, have also shown that 30-65\% of the leukocytes in atherosclerotic plaques are $\mathrm{T}$ cells in both humans and mice ${ }^{18,19,21}$. Although these techniques are fairly destructive during the cell isolation step, favouring the survival of $\mathrm{T}$ cells over macrophages and vascular smooth muscle cells, these findings should not be underestimated ${ }^{21,22}$. T cells might have a substantially greater role in the pathogenesis of atherosclerosis than previously conceived.

$\mathrm{T}$ cells are designed to sense, interact with and respond to their environment. In the circulation, this environment comprises many factors, including but not limited to other immune cells, the vascular wall, chemokines, cytokines and lipids ${ }^{23}$. In this Review, we focus on the interactions that occur between $\mathrm{T}$ cells and circulating lipids that might modulate the immune 


\section{Key points \\ - Fatty acids in the circulation can affect T cell function. \\ - Saturated fatty acids generally induce pro-inflammatory responses in T cells, whereas unsaturated fatty acids generally induce anti-inflammatory responses. \\ - Changes in T cell metabolism underlie the fatty acid-induced alterations in T cell activation, proliferation and polarization. \\ - Fatty acid-induced alterations in T cell function can in turn influence the development and progression of atherosclerosis. \\ - Exposure to fatty acids in the circulation leads to metabolic reprogramming of the $\mathrm{T}$ cells that might predetermine the subsequent role of the $\mathrm{T}$ cell in disease processes.}

$\mathrm{T}_{\mathrm{H}} 17$ cells

A subtype of $\mathrm{CD} 4^{+} \mathrm{T}$ cell

characterized by the expression

of the transcription factor

RORyt and the production of

pro-inflammatory cytokines,

such as IL-17A. The role of

$\mathrm{T}_{\mathrm{H}} 17$ cells in atherosclerosis

is undefined because they

have been found to have

both pro-atherogenic and

anti-atherogenic properties.

Regulatory T cells

$T$ cell characterized by the

expression of the transcription

factor FOXP3 and the secretion

of anti-inflammatory cytokines,

such as IL-10 and TGF $\beta$.

$\mathrm{T}_{\text {reg }}$ cells have been shown

to have anti-atherogenic

functions

T cell tolerance $T$ cells that are reactive to

self-antigens. Tolerance can be induced by exposure to high

doses of an antigen, which results in deletion or anergy

of the $T$ cells that are specific for that antigen.

Triglycerides

Esters formed by a glycerol and three fatty acid groups. High circulating levels of

triglycerides have been

associated with an increased

risk of cardiovascular disease
( $\mathrm{T}_{\text {reg }}$ cells). A subtype of $\mathrm{CD} 4^{+}$

The process of eliminating

responses underlying atherosclerosis development and progression ${ }^{10}$. For example, antigens derived from LDL particles, which are widely associated with atherosclerosis development, are recognized by $\mathrm{T}$ cells in atherosclerotic plaques ${ }^{9,24,25}$. Moreover, $T$ cell tolerance to LDL can be induced in a $\mathrm{T}_{\text {reg }}$ cell-mediated manner by continuously exposing $\mathrm{Ldll}^{-/-}$mice to the primary apolipoprotein of LDL, ApoB-100, which leads to a reduction in atherosclerosis ${ }^{26-29}$. However, the precise consequences in atherosclerosis of the $\mathrm{T}$ cell interactions with lipids have not yet been elucidated.

A type of circulating lipid with which $\mathrm{T}$ cells can interact is triglycerides, which in the past decade have re-emerged as an important risk factor for atherosclerosis ${ }^{30-33}$. The role of triglycerides in CVD is still debated because clinical trials aimed at improving CVD by lowering triglyceride levels in the plasma have had opposing results. The findings of these clinical trials have been summarized previously ${ }^{34}$. Some triglyceride-lowering drugs have been shown to reduce the risk of CVD development ${ }^{34-36}$. The REDUCE-IT trial $^{37,38}$ showed a significant reduction in the risk of adverse cardiovascular events with treatment with the polyunsaturated fatty acid (PUFA) icosapent ethyl, which lowers plasma triglyceride levels, compared with placebo. Triglycerides are composed of fatty acids (FAs) and polar lipids, which are hydrolysed into their FA components and used as a source of energy production in cells ${ }^{39,40}$. Triglycerides are incorporated into chylomicrons after intestinal uptake and transported via the mesenteric lymph to the circulation. FAs are essentially the functional components of triglycerides and as such, the development and progression of atherosclerosis is tied to the various FAs present in the circulation. The effect of different FAs on the risk of

\footnotetext{
Author addresses

${ }^{1}$ Molecular Epidemiology, Department of Biomedical Data Sciences, Leiden University Medical Centre, Leiden, Netherlands.

2Department of Cardiology, Leiden University Medical Centre, Leiden, Netherlands.

${ }^{3}$ Department of Medical Biochemistry, Amsterdam University Medical Centre,

Amsterdam, Netherlands.

${ }^{4}$ Institute for Cardiovascular Prevention (IPEK), Ludwig-Maximilians Universität,

Munich, Germany.

${ }^{5}$ German Centre for Cardiovascular Research (DZHK), partner site Munich Heart Alliance, Munich, Germany.

${ }^{6}$ Leiden Academic Centre for Drug Research, Division of Biotherapeutics, Leiden

University, Leiden, Netherlands.

${ }^{7}$ Netherlands Heart Institute, Utrecht, Netherlands.

${ }^{8}$ These authors jointly supervised: Bastiaan T. Heijmans, J. Wouter Jukema.
}

atherosclerotic CVD ranges from pro-atherosclerotic to anti-atherosclerotic depending on the $\mathrm{FA}^{41-57}$. In this Review, we do not provide evidence to close the debate about the role of triglycerides in CVD but instead aim to uncover and clarify the role of FAs in CVD, which might help in the development of future approaches for the treatment and prevention of atherosclerotic CVD.

FAs are ubiquitously present throughout the body and interact with $\mathrm{T}$ cells, particularly in T cell-rich lymphatic vessels and the blood circulation ${ }^{58,59}$. FAs are composed of a carboxyl group with a carbon chain of various lengths. FAs are classified according to the number of double bonds in the carbon chain: saturated fatty acids (SFAs) have no double bonds, monounsaturated fatty acids (MUFAs) have one double bond, and PUFAs have more than one double bond. Of note, the double bonds of naturally occurring FAs are almost always in $c i s^{60}$. In the context of atherosclerosis, SFAs are generally considered to be pro-atherogenic, whereas MUFAs and PUFAs are considered to be anti-atherogenic. However, some exceptions have been described ${ }^{61}$. For example, higher plasma levels of the MUFA oleic acid have been associated with a higher risk of CVD in humans ${ }^{42}$. The different findings might be explained by the structural and biological differences between FAs in each group, such as in chain length and branching of methyl groups, which are not taken into account in the conventional classification according to the number of double bonds.

In this Review, we describe the role of FAs that are present in the circulation in determining the metabolic and functional responses of $\mathrm{T}$ cells and the link to the development and progression of atherosclerosis. FAs are known to affect the pathogenesis of atherosclerosis and the risk of CVD; however, these effects were traditionally assumed to be mediated via differential effects of FAs on LDL cholesterol that thus also affect the LDL to HDL ratio $^{62}$. We now know that FAs also affect other aspects of physiology and CVD risk factors, such as high blood triglyceride levels, inflammation and vascular reactivity. Most research on FAs and inflammation has so far focused on monocytes, macrophages and endothelial cells. However, accumulating evidence shows that FAs also modulate $\mathrm{T}$ cell functions and processes. Therefore, understanding the effects of FAs on T cells might be inherent to a better comprehension of the pathogenesis of atherosclerosis.

\section{Fatty acids and $\mathrm{T}$ cell responses}

$\mathrm{T}$ cells are a major cellular component of the atherosclerotic plaque, but before they migrate into the lesion, T cells circulate in the bloodstream and the lymph. $\mathrm{T}$ cells spend much of their lifespan in the circulation, therefore, in this Review, we focus on the FA-induced changes that $\mathrm{T}$ cells undergo in the blood (although similar processes might occur in other tissues) and the role that these changes have in atherosclerosis development and progression.

In the circulation, $\mathrm{T}$ cells are usually in a quiescent or resting state until a strong enough stimulus induces an immune response ${ }^{63-65}$. The response of $\mathrm{T}$ cells can be broadly divided into cell activation, proliferation and polarization, coinciding with a change in metabolism ${ }^{64,65}$. 


\section{Box $1 \mid$ Polarization of $\mathrm{CD4}^{+} \mathbf{T}$ cells}

Polarization is a process that determines the different subsets of the $\mathrm{CD} 4^{+} \mathrm{T}$ cells and occurs during $T$ cell activation and proliferation. This Review focuses on how fatty acids in the circulation influence the polarization into four $C D 4^{+} T$ cell subsets, Thelper $1\left(T_{H} 1\right)$ cells, $T_{H} 2$ cells, $T_{H} 17$ cells and regulatory $T\left(T_{\text {reg }}\right)$ cells, which are the most extensively studied. $T$ cell subsets are identified by the expression levels of specific surface markers and transcription factors and by the cytokines the cells secrete ${ }^{129-131} \cdot T_{H} 1, T_{H} 2, T_{H} 17$ and $\mathrm{T}_{\text {reg }}$ cells are defined by the expression of the transcription factors T-bet (also known as TBX21), GATA3, ROR $\gamma t$ and FOXP3, respectively ${ }^{132,133}$. The signature cytokines of $\mathrm{T}_{H} 1$ cells include interferon- $\gamma$ (IFN $\gamma$ ), IL-2 and tumour necrosis factor (TNF). Those of $\mathrm{T}_{\mathrm{H}} 2$ cells are IL-4, IL-5 and IL-13. $\mathrm{T}_{\mathrm{H}} 17$ cells secrete IL-17A, and $\mathrm{T}_{\text {reg }}$ cells produce transforming growth factor- $\beta$ (TGF $\beta$ ) and IL-10. Given that IFN $\gamma$, IL-2, TNF and IL-17A are considered to be pro-inflammatory cytokines, $\mathrm{T}_{\mathrm{H}} 1$ cells and $\mathrm{T}_{\mathrm{H}} 17$ cells are generally considered to be pro-inflammatory T cell subsets ${ }^{134,135}$. IL-4, IL-5, IL-10, IL-13 and TGF $\beta$ are generally deemed to be anti-inflammatory and, therefore, $\mathrm{T}_{\text {reg }}$ cells and $\mathrm{T}_{\mathrm{H}} 2$ cells are classified as anti-inflammatory, but in the context of atherosclerosis, the effect of $\mathrm{T}_{\mathrm{H}} 2$ cells is unclear ${ }^{12,136,137}$. In addition, $\mathrm{T}_{\mathrm{H}} 2$ cells cannot be considered to have only anti-inflammatory functions, because these cells have a role in the pathogenesis of inflammatory diseases such as asthma ${ }^{138}$.

The proper balance of different T cell subsets is very important for an appropriate and effective immune response. Alterations to this balance can lead to a variety of inflammatory and autoimmune diseases, such as rheumatoid arthritis and type 1 diabetes mellitus ${ }^{113,139,140}$. Atherosclerosis is primarily a lipid-driven immunological disease but with a large inflammatory component ${ }^{113}$. Therefore, maintaining a proper balance of T cell subsets is crucial in atherosclerosis as well. Alterations to the balance of T cell subsets occur for several reasons, such as changes in the cytokine milieu or the gut microenvironments ${ }^{132}$. In addition, the effects of circulating fatty acids on T cell activation and proliferation might be linked to the outcome of atherosclerosis. T cell exposure to fatty acids in the circulation might induce changes in T cell polarization, disrupting the T cell subset balance and providing another mechanism for atherosclerosis attenuation or worsening.

Polyunsaturated fatty acid (PUFA). A fatty acid with a carbon chain that contains two or more double bonds. These fatty acids have a primarily anti-atherogenic effect.

Saturated fatty acids (SFAs). Fatty acids with a carbon chain that contains no double bonds. These fatty acids have a primarily pro-atherogenic effect.

\section{Monounsaturated fatty} acids

(MUFAs). Fatty acids with a carbon chain that contains a single double bond. These fatty acids have both pro-atherogenic and anti-atherogenic effects.

Oxidative phosphorylation The main form of energy production in quiescent $\mathrm{T}$ cells. High amounts of ATP are generated through the uptake of glucose and exogenous fatty acids to ensure cell survival.

Aerobic glycolysis

The main form of energy production in activated $\mathrm{T}$ helper cells, in which glucose is actively consumed to produce ATP and the necessary metabolites for cell growth and proliferation.
The $\mathrm{T}$ cell response is usually initiated by antigen presentation by an antigen-presenting cell, although environmental factors, including but not limited to oxygen tension, glucose availability and FAs, can also influence the $\mathrm{T}$ cell response $\mathrm{s}^{5,66-69}$. The blood and lymph provide a setting rich in these environmental factors. In this Review, we focus solely on exogenous FAs; that is, FAs that are not being produced by the $\mathrm{T}$ cell itself. These FAs are abundant in the circulation and therefore can interact with $\mathrm{T}$ cells and influence each part of their response, and the outcomes differ depending on the type of FA to which the cell is exposed (FIG. 1). We discuss the effects of circulating FAs on the main outcomes of each component of the $\mathrm{T}$ cell response and the link with atherosclerosis. A comprehensive discussion of the mechanisms by which FAs influence these responses, which can include the formation of lipid rafts, $G$ protein-coupled receptors and epigenetic reprogramming, is beyond the scope of this Review. The sections on each aspect of the $\mathrm{T}$ cell response are organized into the effects of specific FAs, from pro-inflammatory to anti-inflammatory effects. Within each inflammatory response, FAs are discussed from SFA to MUFA and PUFA, grouping FAs with similar effects on $\mathrm{T}$ cell responses. The potential effects of short-chain FAs, which are derived from the gut microbiota, are not discussed. The effects of the FAs on $\mathrm{T}$ cells are then related to the known role in atherosclerosis of each FA or T cell. Only the FAs that have been studied in the context of $\mathrm{T}$ cell responses are discussed. TABLE 1 provides an overview of the discussed FAs, their abundance in the circulation, their proposed effect on atherosclerosis (not including T cell effects) and the proposed effect on atherosclerosis on the basis of the effect of the FA on T cell function.

\section{Fatty acids and $\mathrm{T}$ cell metabolism}

$\mathrm{T}$ cell metabolism has a crucial role in all stages of the $\mathrm{T}$ cell lifespan, from quiescence to polarization, and has been extensively reviewed previously ${ }^{70}$. An overview of $\mathrm{T}$ cell metabolism can be found in BOX 2. The role of FA metabolism changes substantially throughout these stages, and inappropriate metabolism reprogramming leads to severe skewing of the $\mathrm{T}$ cell populations ${ }^{71}$ (FIG. 1 a; Supplementary Table 1). A change in metabolism is the driving force of the $\mathrm{T}$ cell immune response and underlies the other three components: activation, proliferation and polarization. Therefore, understanding $\mathrm{T}$ cell metabolism and how it can be influenced by circulating FAs is an integral part of understanding the subsequent $\mathrm{T}$ cell functional outcomes.

Specific inhibitors of FA metabolism, such as rapamycin, C75 and soraphen A, can modulate $\mathrm{T}$ cell polarization ${ }^{72-75}$, although $\mathrm{T}$ cell metabolism can also be directly influenced by surrounding FAs. For example, external FAs can influence the development of $\mathrm{T}_{\mathrm{H}} 17$ cells by modifying $\mathrm{T}$ cell metabolism ${ }^{76}$. In mice, deletion of Acaca, which encodes acetyl-CoA carboxylase 1 (ACC1), results in a decrease in $\mathrm{T}_{\mathrm{H}} 17$ cell numbers, but administration of the pro-atherogenic ${ }^{42}$ MUFA oleic acid at high concentrations $(100 \mu \mathrm{mol} / \mathrm{l})$ restores the $\mathrm{T}_{\mathrm{H}} 17$ polarization of naive $\mathrm{Acaca}^{-/-} \mathrm{T}$ cells in vitro ${ }^{76}$. Lower concentrations of the SFAs myristic acid $(30 \mu \mathrm{mol} / \mathrm{l})$ and lauric acid $(10 \mu \mathrm{mol} / \mathrm{l})$ or the PUFA docosahexaenoic acid (DHA) $(1 \mu \mathrm{mol} / \mathrm{l})$ did not rescue the $\mathrm{T}_{\mathrm{H}} 17$ polarization in vitro ${ }^{76}$. Whether the type of FA or the difference in concentrations accounts for the observed differences is unclear. A similar study suggested that the inhibition of $\mathrm{T}_{\mathrm{H}} 17$ polarization induced by the ACC1 inhibitor soraphen A might be rescued by exposure to sufficient levels of the SFA palmitate, although this hypothesis was not formally tested ${ }^{74,75}$.

Oleic acid can also rescue T cell metabolism reprogramming by restoring the rates of oxidative phosphorylation and aerobic glycolysis in mouse $\mathrm{CD} 4^{+} \mathrm{T}$ cells treated with the ACC1 inhibitor TOFA in vitro ${ }^{77}$. Rates of oxidative phosphorylation and glycolysis were measured by the levels of oxygen and protons, respectively, in the culture medium ${ }^{77}$. Under FA-free conditions, the addition of $100 \mu \mathrm{mol} / \mathrm{l}$ oleic acid restored both oxidative phosphorylation and glycolysis ${ }^{77}$. If $\mathrm{CD} 4^{+} \mathrm{T}$ cells can use extrinsic FAs as oxidative substrates for energy production to compensate for blocked metabolic pathways, this compensatory process might also occur in atherosclerotic plaques, which could promote the development of pro-inflammatory effector T cell subsets.

Not all supplemented FAs have been shown to rescue $\mathrm{T}$ cell metabolism, some alter $\mathrm{T}$ cell metabolism and lead to cell death. For example, in C57BL/6 mice, a diet with $12 \%$ weight for weight $(\mathrm{w} / \mathrm{w})$ of the PUFA linoleic acid resulted in $\mathrm{CD}_{4}^{+} \mathrm{T}$ cell death but did not affect $\mathrm{CD} 8^{+}$ $\mathrm{T}$ cell viability ${ }^{78}$. The $\mathrm{CD} 4^{+} \mathrm{T}$ cell death might occur through upregulation of FA oxidation and dysregulation of the electron transport chain. Indeed, exposure 


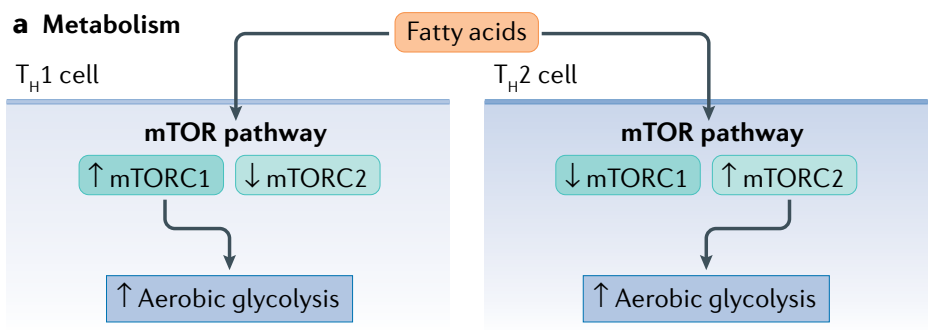

\section{b Activation}
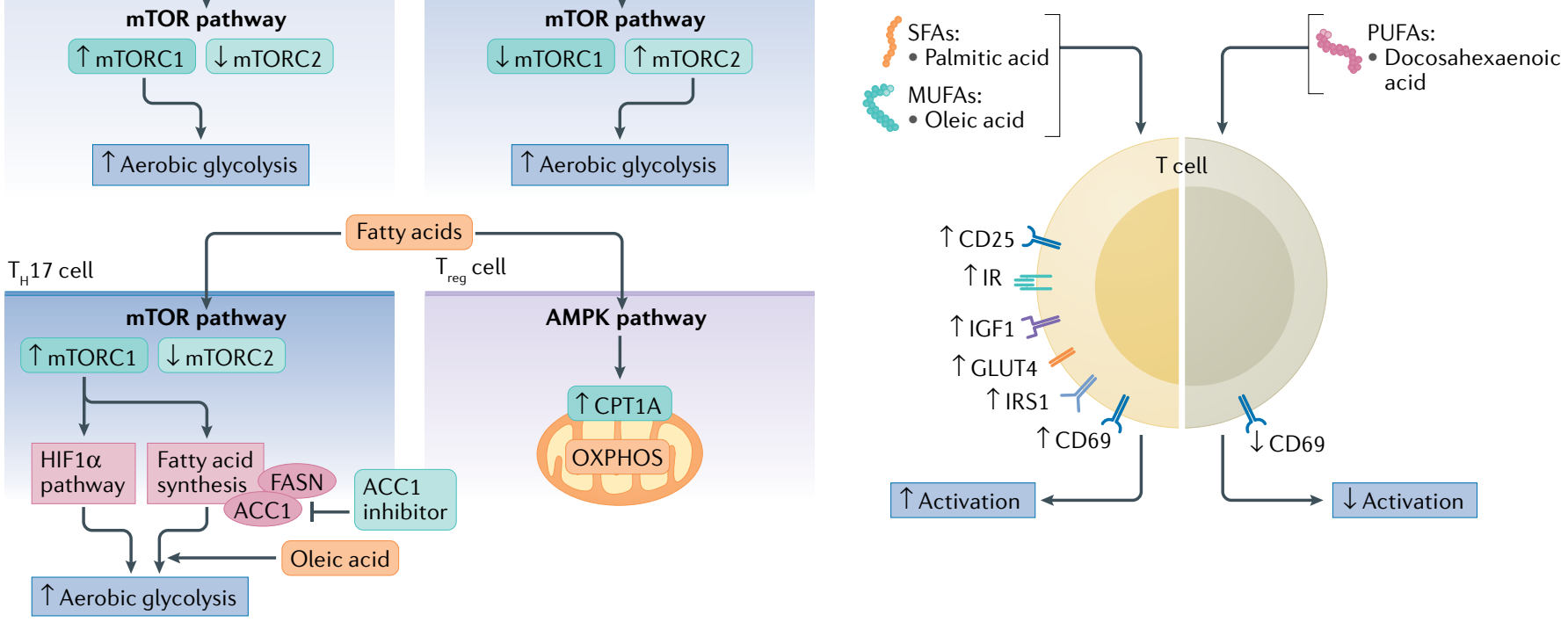

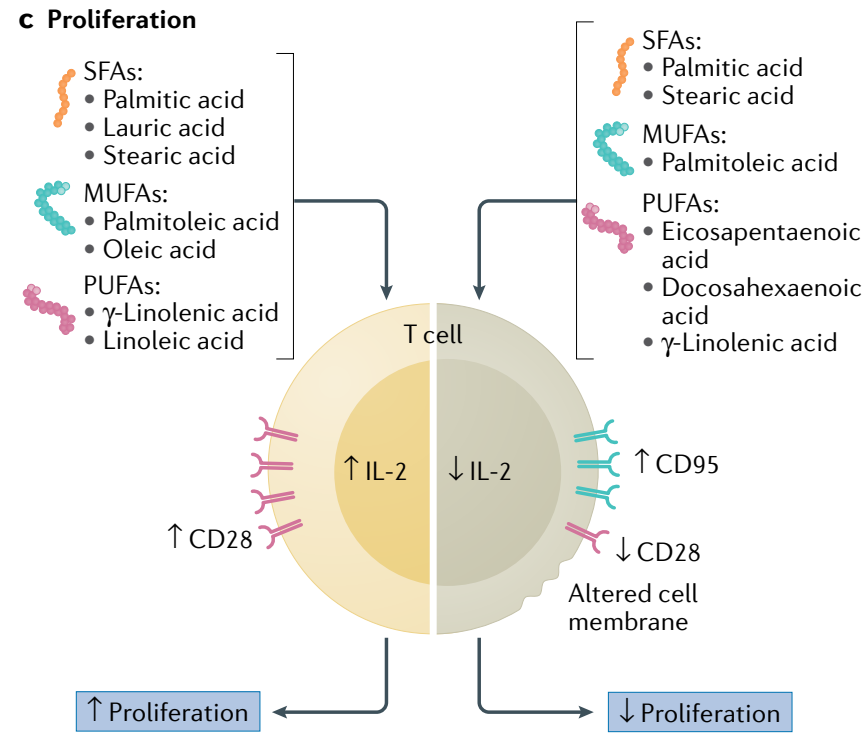

Fig. 1 | Fatty acids alter T cell function by influencing their metabolism, activation, proliferation and polarization. Generally, monounsaturated fatty acids (MUFAs) and polyunsaturated fatty acids (PUFAs) induce anti-inflammatory responses in T cells whereas saturated fatty acid (SFAs) induce pro-inflammatory responses, although some discrepancies have been observed, such as with oleic acid. The yellow background indicates increased activity, such as increased activation and proliferation or a pro-inflammatory response. The grey background indicates decreased activity, such as decreased activation and proliferation or an anti-inflammatory response. a | The metabolism of activated T cells is different depending on the T cell subset. The panel shows the four main subsets of $\mathrm{CD} 4^{+} T$ cells. During polarization, the effector $T$ cells $T$ helper $1\left(T_{H} 1\right)$ cells, $T_{H} 2$ cells and $T_{H} 17$ cells switch to aerobic glycolysis, whereas regulatory $T\left(T_{\text {reg }}\right)$ cells maintain oxidative phosphorylation (OXPHOS). The blockade in $\mathrm{T}_{\mathrm{H}} 17$ cell polarization caused by inhibition of the enzyme acetyl-CoA carboxylase 1 (ACC1) can be rescued in vitro by the addition of oleic acid. $\mathbf{b}$ | Exposure to SFAs or MUFAs induces T cell activation, as measured by increased levels of cell-surface receptors, including insulin receptor (IR), insulin-like growth factor 1 (IGF1), glucose transporter type 4

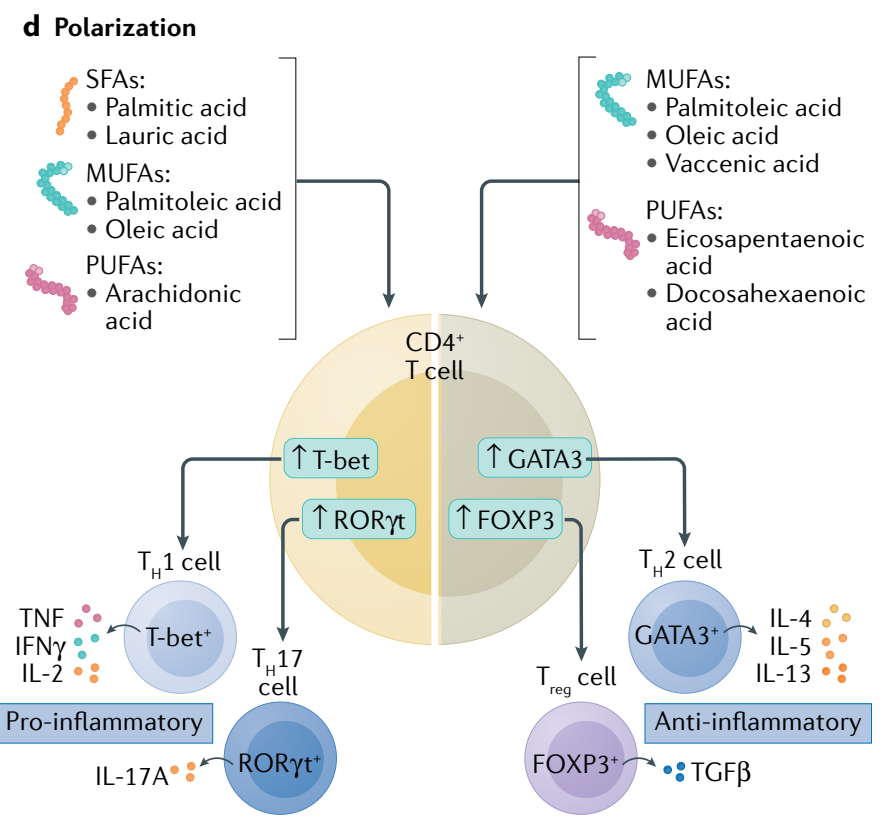

(GLUT4) and insulin receptor substrate 1 (IRS1), compared with untreated cells. By contrast, PUFAs inhibit activation, as measured by decreased levels of cell-surface receptors compared with untreated cells. c | Different SFAs, MUFAs and PUFAs differentially increase or decrease T cell proliferation. The effects of fatty acids on proliferation influence the numbers of specific $T$ cell subsets in atherosclerotic plaques, as shown in experimental studies. d|PUFAs generally promote $T$ cell polarization into the anti-inflammatory $T$ cell subsets $\mathrm{T}_{\text {reg }}$ cells and $\mathrm{T}_{\mathrm{H}} 2$ cells. Conversely, SFAs and MUFAs generally promote $\mathrm{T}$ cell polarization into pro-inflammatory subsets, such as $T_{H} 1$ cells and $T_{H} 17$ cells. The different $T$ cell subsets then produce their signature cytokines, which can be measured for subset identification in experimental studies. See the main text for more information. AMPK, AMP-activated protein kinase; CPT1A, carnitine O-palmitoyltransferase 1; FASN, fatty acid synthase; FOXP3, forkhead box protein P3; GATA3, GATA-binding factor 3; HIF1a, hypoxia-inducible factor $1 \alpha$; IFN $\gamma$, interferon- $\gamma ;$ mTOR, mechanistic target of rapamycin; mTORC, mechanistic target of rapamycin complex; ROR $\gamma t$, nuclear receptor ROR $\gamma \mathrm{t}$; T-bet, T-box transcription factor TBX21; TGF $\beta$, transforming growth factor- $\beta$; TNF, tumour necrosis factor. 
Table 1 | Effects of circulating fatty acids on atherosclerosis

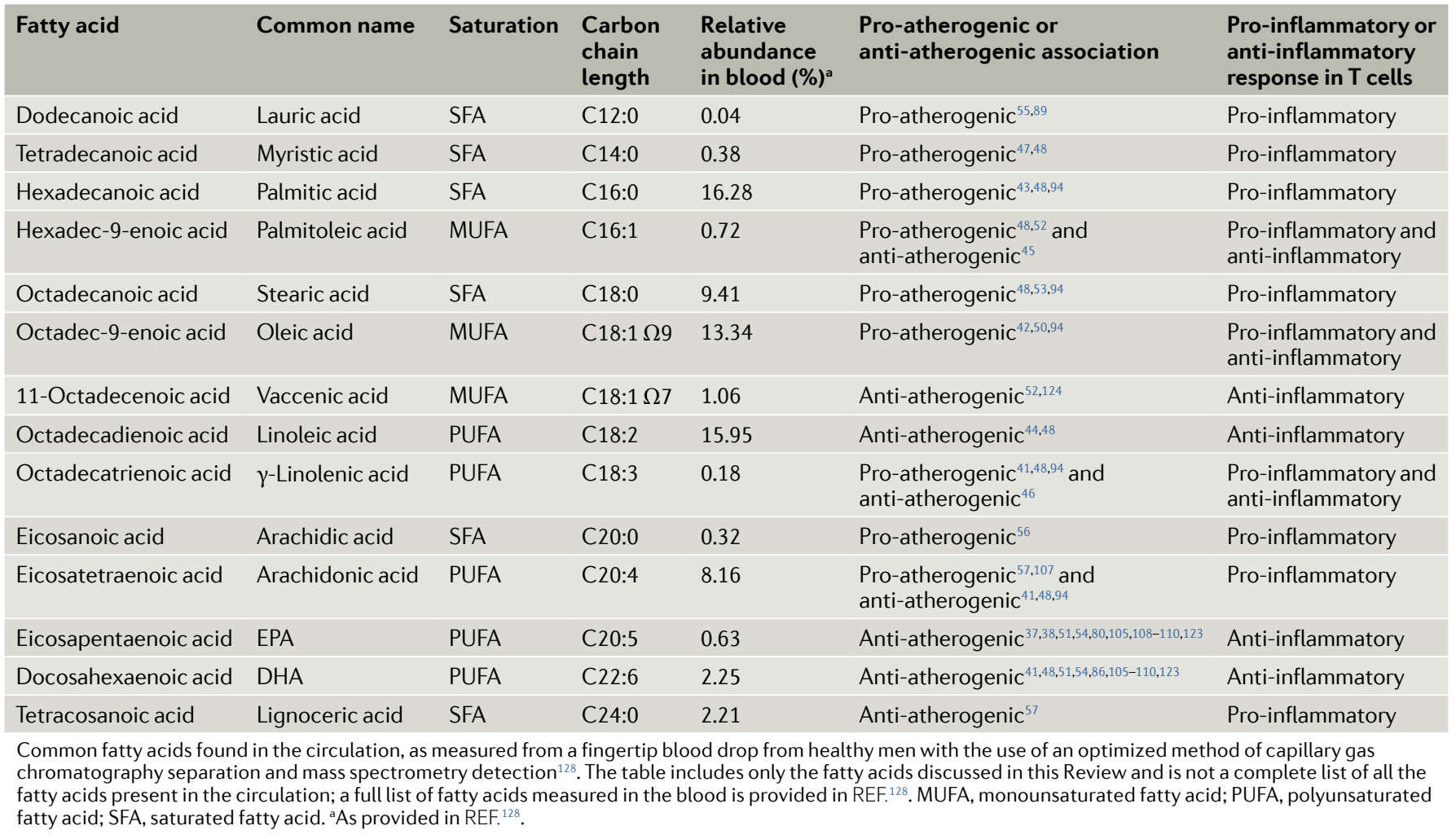

of $\mathrm{CD}^{+} \mathrm{T}$ cells isolated from transgenic mice with an inducible liver-specific $M Y C$ oncogene (which overexpress $M Y C$ and are used as a model of non-alcoholic fatty liver disease) to $50 \mu \mathrm{mol} / \mathrm{l}$ of linoleic acid in vitro increased the expression of genes encoding proteins involved in FA oxidation, whereas the expression of genes encoding components of the electron transport chain was decreased ${ }^{78}$. These transcriptional changes have a negative effect on $\mathrm{T}$ cell function because FAs are actively $\beta$-oxidized in the mitochondria, which favours more $\mathrm{NADH}$ entering the electron transport chain to produce ATP. However, because the electron transport chain is disrupted, premature leakage of electrons to oxygen can generate the accumulation of reactive oxygen species and lead to cell death or apoptosis ${ }^{78}$. Therefore, linoleic acid might have anti-inflammatory effects by inducing a pro-apoptotic phenotype in $\mathrm{CD} 4^{+}$ $\mathrm{T}$ cells and reducing this $\mathrm{T}$ cell population. Other PUFAs also might induce a pro-apoptotic phenotype in $\mathrm{T}$ cells through alterations in $\mathrm{T}$ cell metabolism. Exposure of human $\mathrm{CD}^{+} \mathrm{T}$ cells in vitro to $50 \mu \mathrm{mol} / \mathrm{l}$ of eicosapentaenoic acid (EPA) or DHA for $48 \mathrm{~h}$ led to increased proton leakage associated with mitochondrial respiration ${ }^{79}$, a pro-apoptotic signature. Furthermore, the ratio of oxidative phosphorylation to glycolysis was reduced in these cells, which has been linked to suppressed proliferation.

Of note, linoleic acid, EPA and DHA have all been shown to have anti-atherogenic effects in humans, mice and in vitro models ${ }^{41,44,80}$. However, in humans, the concentrations of these PUFAs in atherosclerotic plaques are lower than in the serum ${ }^{81}$. By contrast, the concentrations of pro-atherogenic SFAs and MUFAs such as oleic acid are similar or higher in human atherosclerotic plaques than in the serum ${ }^{81}$. This observation provides a partial explanation for the skewed polarization towards pro-inflammatory $\mathrm{T}$ cell subsets observed in atherosclerotic plaques in humans and animal models ${ }^{11,12}$.

Taken together, these studies provide evidence that external FAs are involved in the metabolic reprogramming of $\mathrm{T}$ cells. This metabolic reprogramming underlies the activation, proliferation and polarization of $\mathrm{T}$ cells, leading to changes in $\mathrm{T}$ cell function that can influence their eventual role in diseases such as atherosclerosis.

\section{Fatty acids and $\mathbf{T}$ cell activation}

$\mathrm{T}$ cell activation is a multifaceted response that follows a complex signalling cascade in the $\mathrm{T}$ cell. A detailed description of $\mathrm{T}$ cell activation has been provided previously ${ }^{65}$. Briefly, the T cell receptor (TCR) binds to an antigen presented by an antigen-presenting cell to induce a cellular response ${ }^{82}$. Binding of the TCR to an antigen, together with simultaneous stimulation of the CD3 and co-stimulatory molecules leads to the activation of T cells ${ }^{65}$. A summary of the effects of FAs on T cell activation is shown in FIG. $1 \mathrm{~b}$ and Supplementary Table 2.

Remarkably, the SFA palmitic acid can induce $\mathrm{T}$ cell activation in vitro in the absence of activating antibodies ${ }^{83}$. CD $4^{+} \mathrm{T}$ cells or $\mathrm{CD} 8^{+} \mathrm{T}$ cells isolated from five individuals without diabetes mellitus and with normal glucose tolerance were exposed to palmitic acid in vitro. Activation was then determined across five time points by measuring oxidative stress and the expression of the activation markers CD69, insulin receptor, insulin-like growth factor 1, IL-2, glucose transporter type 4 and insulin receptor substrate 1 . Palmitic acid 


\section{Box $2 \mid T$ cell metabolism}

\section{Quiescent T cells}

Quiescent T cells have high energetic demands and, therefore, focus their metabolism on ATP generation through oxidative phosphorylation and $\beta$-oxidation of fatty acids ${ }^{63}$. These catabolic processes are driven by the uptake of glucose and exogenous fatty acids for mitochondrial metabolism, which is regulated by the AMP-activated protein kinase (AMPK) pathway and the rate-limiting factor carnitine $O$-palmitoyltransferase 1 (CPT1A), which regulates lipid uptake into the mitochondria ${ }^{63,141}$.

\section{Activated T cells}

Activation and proliferation are characterized by rapid expansion of the $T$ cell population for which T cells must produce energy rapidly and simultaneously create the necessary metabolites to sustain growth ${ }^{142}$. Therefore, activated T cells undergo a metabolic switch to the anabolic processes of aerobic glycolysis and fatty acid biosynthesis, known as the Warburg effect ${ }^{143}$. Aerobic glycolysis yields only two ATPs per molecule of glucose instead of the 36 ATPs that are achieved with oxidative phosphorylation. Nevertheless, this metabolic switch is required to produce the necessary metabolites for sustained cell growth and proliferation ${ }^{63,141,142}$. The mechanistic target of rapamycin (mTOR) pathway has a crucial role in the metabolic reprogramming of $\mathrm{T}$ cells by inducing the expression of genes related to lipid biosynthesis and decreasing the expression of CPT1 $A^{77}$. Without CPT1A to actively pump lipids into the mitochondria for oxidation and ATP production, the lipids can be conserved for cell growth.

\section{Regulatory T cells}

Regulatory $T\left(T_{\text {reg }}\right)$ cells are almost completely reliant on oxidative phosphorylation and $\beta$-oxidation of fatty acids through maintaining the activation of the AMPK pathway and expression of CPT1 $A^{141,14,145}$. However, under conditions of high lipid concentrations, the AMPK pathway is downregulated, gradually impairing $\mathrm{T}_{\text {reg }}$ cell function and numbers ${ }^{146,147}$. This observation potentially explains why advanced atherosclerotic plaques do not contain high numbers of $\mathrm{T}_{\text {reg }}$ cells and are instead dominated by effector $\mathrm{T}$ cells, in both humans and mice ${ }^{10,137,147}$. A dyslipidaemic environment, as found in atherosclerosis, might promote the polarization into effector $\mathrm{T}$ cells and reduce $\mathrm{T}_{\text {reg }}$ cell polarization $^{148-151}$.

\section{Effector T cells}

The polarization of effector $T$ cells ( $T$ helper $1\left(T_{H} 1\right)$ cells, $T_{H} 2$ cells and $T_{H} 17$ cells) is highly dependent on anabolic metabolism and the mTOR pathway ${ }^{141}$. Inhibition of this pathway eliminates effector T cells in mice ${ }^{72,152}$. The mTOR pathway comprises two complexes, mTOR complex 1 (mTORC1) and mTORC2. $\mathrm{T}_{\mathrm{H}} 1$ and $\mathrm{T}_{\mathrm{H}} 17$ cells are dependent on $m$ TORC1, whereas $T_{H} 2$ cells are dependent on $m$ TORC2 (REF. ${ }^{153}$ ). In mice, deletion of Rheb (which encodes a protein required for mTORC1 activation) results in the inhibition of $T_{H} 1$ and $T_{H} 17$ polarization, whereas deletion of Rictor (which encodes a component of mTORC2) results in the inhibition of $\mathrm{T}_{\mathrm{H}} 2$ polarization ${ }^{153} . \mathrm{T}_{\mathrm{H}} 17$ cells are dependent on the hypoxia-inducible factor $1 a$ pathway and de novo fatty acid synthesis ${ }^{154}$. Fatty acid synthesis is controlled by the enzymes fatty acid synthase (FASN) and acetyl-CoA carboxylase 1 (ACC1). In mice, knockout of Fasn skews $T$ cell polarization towards $T_{H} 1$ cells, whereas ACC1 inhibition skews polarization towards $T_{\text {reg }}$ cells ${ }^{73-75}$. Therefore, subtle changes in T cell metabolism can greatly alter subset polarization.

A detailed overview of T cell metabolism is provided in REF. ${ }^{70}$.

( $50 \mu \mathrm{mol} / \mathrm{l}$ and $500 \mu \mathrm{mol} / \mathrm{l})$ induced time-dependent and concentration-dependent activation of the $\mathrm{T}$ cells. This effect was not observed with exposure to the MUFA oleic acid or the PUFAs linoleic acid, linolenic acid and arachidonic acid ${ }^{83}$. Palmitic acid can be categorized as pro-atherogenic ${ }^{43}$. Weaning male $L d l r^{-1-}$ mice fed a diet enriched in an interesterified palmitic acid had greater atherosclerosis burden and lesion area than mice fed high-fat diets enriched in PUFAs, palmitic acid, stearic acid or interesterified stearic acid ${ }^{43}$. The researchers attributed this effect to higher cholesterol accumulation in LDL particles and macrophages, but did not consider the effect that this diet might have had on other immune cells, such as T cells, and how these cells could have affected disease progression ${ }^{43}$.

Oleic acid is also generally considered to be proatherogenic because elevated levels of oleic acid in the plasma are an independent risk factor for $\mathrm{CVD}^{42}$. The effect of oleic acid on $\mathrm{T}$ cell activation might contribute to this observation. The proportion of splenic T lymphocytes expressing CD25 (a T cell activation marker) was significantly higher in male Wistar rats fed a diet in which $12 \%$ of the total energy came from a lipid emulsion rich in oleic acid (53\%) than in rats fed a diet in which $12 \%$ of the total energy came from a lipid emulsion rich in linoleic acid $(51 \%)^{84}$. The number of CD $25^{+}$ cells was measured by fluorescence-activated cell sorting and correlated with the oleic acid content in the lipid emulsion, indicating a potential role of this FA in $\mathrm{T}$ cell activation $^{84}$.

FAs can also decrease $\mathrm{T}$ cell activation. In a study in healthy human volunteers, supplementation with the PUFA DHA (nine capsules of $1 \mathrm{~g}$ of fish oil enriched in DHA per day over 4 weeks) specifically reduced $\mathrm{T}$ cell activation compared with placebo, as measured by a decrease in CD69 expression in T cells. No reduction in the percentage of cells participating in phagocytosis or expressing adhesion molecules was observed in the monocyte or neutrophil fractions of the samples, as measured by fluorescence flow cytometry ${ }^{85}$. DHA is generally classified as anti-atherogenic because dietary intake of DHA has been shown to decrease heart rate, blood pressure and the plasma levels of LDL particles in humans, and high plasma levels of DHA are associated with a lower risk of developing carotid atherosclerotic plaques, all of which are associated with a reduced risk of atherosclerosis development ${ }^{54,86}$. Understanding the transformative effects of a specific FA on the T cell response and how the FA is related to CVD allows us to begin to link the effects of FAs on T cells to atherosclerosis.

\section{Fatty acids and $\mathrm{T}$ cell proliferation}

A brief growth phase occurs after T cell activation, followed by a rapid expansion of the $\mathrm{T}$ cell population, referred to as proliferation ${ }^{87}$. Like activation, this proliferation phase can also be influenced by the interaction with FAs (FIG. 1c; Supplementary Table 3). Male C57BL/ 6 mice fed a chow diet containing $31 \%$ crude fat, of which $13.5 \%$ was the SFA lauric acid, had increased $\mathrm{T}$ cell proliferation without any additional $\mathrm{T}$ cell activation compared with mice fed a control chow diet (4.2\% crude fat ${ }^{88}$. In healthy individuals, lauric acid generally comprises only about $0.04 \%$ of circulating FAs (TABLE 1) but, as the previously described study in mice showed, a high intake of this SFA can lead to an increase in $\mathrm{T}$ cell proliferation, which might be important when considering that lauric acid makes up approximately $50 \%$ of widely consumed products such as coconut oil ${ }^{89}$.

$\mathrm{T}$ cell proliferation can also be increased by other FAs that are present at higher levels in the circulation. Oleic acid, which comprises about $13 \%$ of circulating FAs (TABLE 1), can also increase the proliferation of T cells in vitro. In an in vitro study, T cells isolated from healthy men showed a $17 \%$ increase in proliferation after exposure to $25 \mu \mathrm{mol} / \mathrm{l}$ oleic acid for $30 \mathrm{~h}$ compared with control cells ${ }^{90}$. The addition of $25 \mu \mathrm{mol} / \mathrm{l}$ oleic or linoleic acid to human lymphocytes in the presence of the activator concanavalin A also increased proliferation in vitro ${ }^{91}$. 
An in vivo study showed increased proliferation of lymphocytes in male Wistar rats after intraduodenal administration of $5 \mathrm{ml}$ of an oleic acid solution ${ }^{92}$. Similarly, exposure to palmitic acid, palmitoleic acid, stearic acid, oleic acid, linoleic acid or $\gamma$-linolenic acid increased the proliferation of activated human $\mathrm{CD}^{+} \mathrm{T}$ cells in vitro ${ }^{93}$ (Supplementary Table 3). Palmitic acid, stearic acid and oleic acid can be considered to be pro-atherogenic, whereas palmitoleic acid, linoleic acid and $\gamma$-linolenic acid can be considered to be anti-atherogenic ${ }^{42-46,94}$. However, all these FAs increase $\mathrm{T}$ cell proliferation. These findings might indicate that different $\mathrm{T}$ cell subsets proliferate with either a more pro-inflammatory or anti-inflammatory phenotype, thereby leading to atherosclerosis aggravation or amelioration, highlighting the importance of understanding not only the effects of FAs on T cells, but also how they affect atherosclerosis. In addition, the FA concentrations to which $\mathrm{T}$ cells are exposed might influence the observed effects on proliferation. In the described studies, $\mathrm{T}$ cell proliferation was increased after exposure to $4 \mu \mathrm{g} / \mathrm{ml}$ of the SFAs palmitic acid or stearic acid ${ }^{93}$ (Supplementary Table 3). However, a decrease in proliferation was found in human lymphocytes in vitro after the addition of $50 \mu \mathrm{mol} / \mathrm{l}$ palmitic acid or stearic acid $^{91}$, which is equivalent to about $12 \mu \mathrm{g} / \mathrm{ml}$ and $14 \mu \mathrm{g} / \mathrm{ml}$, respectively. At these concentrations, $\mathrm{T}$ cell proliferation was reduced via an IL-2-mediated pathway ${ }^{91}$. Palmitic acid and stearic acid have both been suggested to have pro-atherogenic effects, although this effect might be mediated in a T cell-independent manner ${ }^{43,94}$.

The effect of the MUFA palmitoleic acid on $\mathrm{T}$ cell proliferation might also be concentration-dependent. Human $\mathrm{CD}^{+} \mathrm{T}$ cell proliferation in vitro was increased after the addition of $2 \mu \mathrm{g} / \mathrm{ml}$ palmitoleic acid $^{93}$, as discussed above (Supplementary Table 3). However, addition of $25 \mu \mathrm{mol} / 1$ or $50 \mu \mathrm{mol} / 1$ of this MUFA (equivalent to $6 \mu \mathrm{g} / \mathrm{ml}$ and $13 \mu \mathrm{g} / \mathrm{ml}$, respectively) for $30 \mathrm{~h}$ to $\mathrm{T}$ lymphocytes in vitro induced a $50 \%$ decrease in proliferation ${ }^{90}$. These concentrations were not cytotoxic, as evaluated by membrane integrity and phosphatidylserine externalization assays, but induced a decrease in the expression of CD28 (an activation marker) and an increase in the expression of CD95 (which is involved in the initial steps of apoptosis) ${ }^{90}$. The reduction in activation markers and the increase in suppressor markers in the $\mathrm{T}$ cells provides a possible explanation for the observed decrease in proliferation $^{90}$. Palmitoleic acid has been suggested to have anti-atherogenic effects ${ }^{45}$. This effect could be mediated through the anti-proliferative effect of this FA on pro-inflammatory $\mathrm{T}$ cell subsets and its proliferative effect on anti-inflammatory $\mathrm{T}$ cell subsets, which is discussed in more detail in the next section.

The effect of the PUFA $\gamma$-linolenic acid might depend on the timing of exposure relative to $\mathrm{T}$ cell activation. This FA reduced $\mathrm{T}$ cell proliferation in healthy humans in vivo $5 \mathrm{~h}, 24 \mathrm{~h}$ and $48 \mathrm{~h}$ after a single oral administration of $2.4 \mathrm{~g}$ (REF. $\left.{ }^{95}\right)$. Furthermore, the addition of $5-25 \mu \mathrm{g} / \mathrm{ml}$ of $\gamma$-linolenic acid in vitro before, but not during, T cell activation also inhibited proliferation ${ }^{96}$. By contrast, proliferation increased when $\gamma$-linolenic acid was added to activated $\mathrm{CD} 4^{+} \mathrm{T}$ cells from healthy human donors ${ }^{93}$. $\gamma$-Linolenic acid is considered to be anti-atherogenic through inhibition of monocyte migration and foam cell formation ${ }^{46}$. However, further investigation of the potential anti-atherogenic effects of $\gamma$-linolenic acid on T cells is warranted. The results discussed here underline the complexity of translating in vitro findings to the in vivo situation.

Two FAs have been consistently shown to decrease $\mathrm{T}$ cell proliferation across different studies, concentrations and time points, namely the PUFAs EPA and DHA. This effect has been shown in several studies involving human, mouse and rat $\mathrm{T}$ cells in vitro and in vivo ${ }^{79,91,97-104}$. How exactly these two FAs induce this response is still unknown, although a speculative hypothesis is that inhibition of IL-2 production, which is necessary for proliferation, and alterations in the structure of the cell membrane are involved ${ }^{79,91,97-101}$. Both EPA and DHA have been shown in numerous studies to decrease atherosclerosis development in both human and animal models ${ }^{51,54,80,105-110}$. The observation that these FAs decrease $\mathrm{T}$ cell proliferation in vitro and the capacity of DHA to reduce $\mathrm{T}$ cell activation in vitro together with the finding that they protect against atherosclerosis development indicate that these FAs, T cells and atherosclerosis reduction might be linked.

FAs are an integral component of $\mathrm{T}$ cell proliferation regardless of whether they increase or decrease it. Without FAs, T cell proliferation is inhibited, meaning the $\mathrm{T}$ cells cannot replicate owing to a lack of available resources to generate more cells. This inhibition occurs in T cells cultured under FA-free conditions, but the addition of certain FAs rescues the proliferation. Specifically, the addition of $100 \mu \mathrm{mol} / \mathrm{l}$ of oleic acid, myristic acid, palmitic acid or arachidic acid rescued proliferation of $\mathrm{CD} 4^{+} \mathrm{T}$ cells from humans, BALB/c mice and C57BL/6 mice cultured under FA-free conditions $48 \mathrm{~h}$ after activation ${ }^{77}$. By contrast, the addition of $100 \mu \mathrm{mol} / \mathrm{l}$ of lauric acid, palmitoleic acid, linoleic acid, $\gamma$-linolenic or lignoceric acid did not rescue proliferation under the same conditions ${ }^{77}$. These results mimic the observed effects of these FAs on atherosclerosis, because oleic acid, myristic acid and palmitic acid have all been found to be pro-atherogenic, whereas palmitoleic acid, linoleic acid and $\gamma$-linolenic acid have all been found to be anti-atherogenic in both humans and mice ${ }^{42-48}$. Furthermore, most of the tested SFAs (myristic acid, palmitic acid and arachidic acid) rescued $\mathrm{T}$ cell proliferation in vitro, whereas most of the unsaturated FAs (palmitoleic acid, linoleic acid and linolenic acid) did not $^{77}$. Discrepancies between the capacity of saturated and unsaturated FAs to rescue $\mathrm{T}$ cell proliferation in FA-free conditions further reveals the complexity of the processes by which different FAs alter $\mathrm{T}$ cell function and the difficulty in understanding the effects of these interactions on atherosclerosis.

\section{Fatty acid-mediated $\mathrm{T}$ cell polarization}

Although $\mathrm{T}$ cells differentiate in the thymus, activation and polarization of $\mathrm{T}$ cells occur later at the site of injury or damage. $\mathrm{T}$ cell polarization generates various $\mathrm{T}$ cell subsets, of which the $\mathrm{CD} 4^{+} \mathrm{T}$ cell subsets are discussed 
in more detail below (BOX 1). Different FAs skew the proportions of these populations in distinct directions (FIG. 1d; Supplementary Table 4). SFAs generally induce polarization into pro-inflammatory $\mathrm{CD} 4^{+} \mathrm{T}$ cell subsets. An example is the medium-chain SFA lauric acid. In activated mouse $\mathrm{CD} 4^{+} \mathrm{T}$ cells in vitro under conditions inducing $\mathrm{T}_{\mathrm{H}} 1$ or $\mathrm{T}_{\mathrm{H}} 17$ polarization, the addition of $250-500 \mu \mathrm{mol} / \mathrm{l}$ of lauric acid increased the populations of pro-inflammatory $\mathrm{T}_{\mathrm{H}} 1$ cells and $\mathrm{T}_{\mathrm{H}} 17$ cells by $50 \%$ and decreased the population of anti-inflammatory $\mathrm{T}_{\text {reg }}$ cells by $30 \%^{88}$. In human $\mathrm{CD}^{+} \mathrm{T}$ cells in vitro under conditions inducing $\mathrm{T}_{\mathrm{H}} 1$ or $\mathrm{T}_{\mathrm{H}} 17$ polarization, the addition of $250 \mu \mathrm{mol} / 1$ of lauric acid increased the populations of $\mathrm{T}_{\mathrm{H}} 1$ and $\mathrm{T}_{\mathrm{H}} 17$ cells by $35 \%$ and increased the relative expression of IFNG and TNF, and ILI7A and RORC, respectively. In human $\mathrm{CD} 4{ }^{+} \mathrm{T}$ cells in vitro under conditions inducing $\mathrm{T}_{\text {reg }}$ cell polarization, the addition of $250 \mu \mathrm{mol} / \mathrm{l}$ of lauric acid decreased the population of $\mathrm{T}_{\text {reg }}$ cells and decreased the expression of FOXP3 by $50 \%{ }^{88}$. Additionally, male C57BL/6 mice fed a diet rich in either lauric acid or palmitic acid had higher levels of the cytokines interferon- $\gamma$ (IFN $\gamma$ ) and IL-17A in lamina propria lymphocytes in the small intestine, increased $\mathrm{T}_{\mathrm{H}} 17$ cell numbers in the central nervous system, and increased $T_{H} 1$ cell and $T_{H} 17$ cell numbers in the spleen compared with mice fed a control diet ${ }^{88}$.

Palmitic acid is another SFA that can induce polarization of pro-inflammatory $\mathrm{T}$ cell subsets. The addition of $1 \mathrm{mmol} / \mathrm{l}$ palmitic acid to human peripheral blood mononuclear cells (PBMCs) that had been activated with anti-CD3 and anti-CD28 in vitro increased the proportion of $\mathrm{T}_{\mathrm{H}} 1$ and $\mathrm{T}_{\mathrm{H}} 17$ populations but decreased the proportion of $\mathrm{T}_{\mathrm{H}} 2$ and $\mathrm{T}_{\text {reg }}$ cell populations, as measured by the expression of the subset-specific transcription factors T-bet (also known as TBX21), ROR $\gamma \mathrm{t}$, GATA3 and FOXP3, respectively ${ }^{111}$. Furthermore, similar results were found when PBMCs were exposed to $1 \mathrm{mmol} / \mathrm{l}$ of the MUFA oleic acid or to a combination of $1 \mathrm{mmol} / \mathrm{l}$ oleic acid plus palmitic acid for $48 \mathrm{~h}^{111}$. These results together with the findings discussed in the previous paragraphs indicate that SFAs and some MUFAs promote pro-inflammatory $\mathrm{T}$ cell subset polarization and $\mathrm{T}$ cell proliferation.

In addition to SFAs and some MUFAs, the PUFA arachidonic acid also elicits pro-inflammatory $\mathrm{T}$ cell polarization ${ }^{112}$, even though this PUFA is closely related to the anti-inflammatory PUFAs EPA and DHA. Non-obese diabetic (NOD) mice fed a diet enriched in arachidonic acid had increased $\mathrm{T}_{\mathrm{H}} 1$ and $\mathrm{T}_{\mathrm{H}} 17 \mathrm{popu}$ lations and increased levels of IFN $\gamma$, tumour necrosis factor (TNF) and IL-17A in the plasma compared with NOD mice fed a control diet ${ }^{112}$. The same study also found a drastically disrupted $\mathrm{T}_{\mathrm{H}} 1$ to $\mathrm{T}_{\mathrm{H}} 2$ cell balance. Furthermore, this study found that in vitro exposure of activated $\mathrm{CD} 4^{+} \mathrm{T}$ cells from humans or mice to $100 \mu \mathrm{mol} / \mathrm{l}$ or $50 \mu \mathrm{mol} / \mathrm{l}$ arachidonic acid, respectively, for $24 \mathrm{~h}$ resulted in an increased proportion of $\mathrm{T}_{\mathrm{H}} 1$ and $\mathrm{T}_{\mathrm{H}} 17$ populations and IFN $\gamma$ and IL-17A secretion together with a decrease in the secretion of IL-4 (REF. ${ }^{112}$ ). These findings indicate that arachidonic acid mediates pro-inflammatory responses by influencing $\mathrm{CD} 4^{+} \mathrm{T}$ cell polarization.
Not all MUFAs are strictly pro-inflammatory: palmitoleic acid and oleic acid seem to have mixed pro-inflammatory and anti-inflammatory effects. Palmitoleic acid has partial anti-inflammatory effects on $\mathrm{CD}^{+} \mathrm{T}$ cell polarization by reducing the proportions of $\mathrm{T}_{\mathrm{H}} 1$ and $\mathrm{T}_{\mathrm{H}} 17$ populations ${ }^{90}$. Cytokine profiling using flow cytometry showed that in vitro addition of $25 \mu \mathrm{mol} / \mathrm{l}$ or $50 \mu \mathrm{mol} / \mathrm{l}$ palmitoleic acid to human activated $\mathrm{T}$ cells was not cytotoxic but reduced the production of IL-17A, IL-2, IFN $\gamma$ and TNF ${ }^{90}$. However, these same concentrations of palmitoleic acid also reduced the proportion of the $\mathrm{T}_{\text {reg }}$ cells from $3.5 \%$ to $0.2 \%{ }^{90}$. $\mathrm{T}_{\text {reg }}$ cells have a pivotal role in reducing the inflammatory response and preventing autoimmunity ${ }^{113}$; therefore, a decrease in their population caused by exposure to a specific FA can be interpreted as that FA substantiating pro-inflammatory responses. Oleic acid also has partial pro-inflammatory effects, because $50 \mu \mathrm{mol} / \mathrm{l}$ of oleic acid reduced the proportion of $\mathrm{T}_{\text {reg }}$ cells in vitro in a similar fashion to palmitoleic acid ${ }^{90}$. However, oleic acid has also been found to have partial anti-inflammatory effects: the addition of $25 \mu \mathrm{mol} / 1$ and $50 \mu \mathrm{mol} / \mathrm{l}$ oleic acid reduced IFN $\gamma$ and IL-17A production and increased IL-2, IL-4 and IL-10 production, indicating a partial decrease in $\mathrm{T}_{\mathrm{H}} 1$ and $\mathrm{T}_{\mathrm{H}} 17$ cells and an increase in $\mathrm{T}_{\mathrm{H}} 2$ cells $\mathrm{s}^{90}$.

The above data generally support the classification of palmitoleic acid as being mostly anti-atherogenic, but creates some uncertainty about the findings indicating that oleic acid potentially has pro-atherogenic effects. A study investigating the link between MUFAs and cardiovascular mortality showed a U-shaped association between oleic acid concentrations in erythrocyte membranes and cardiovascular mortality ${ }^{50}$. This observation suggests that oleic acid is associated with cardiovascular mortality only at low and high concentrations in erythrocyte membranes, but less so at medium concentrations, which provides a possible explanation for the occasionally anti-inflammatory effects that oleic acid has on $\mathrm{T}$ cell subset polarization. However, the concentrations of oleic acid used in the various studies described above ranged from $25 \mu \mathrm{mol} / 1$ to $1,000 \mu \mathrm{mol} / \mathrm{l}$, with no clearly distinguishable differences in pro-inflammatory and anti-inflammatory effects based on the concentration used.

Other MUFAs, such as vaccenic acid, have been shown to have solely anti-inflammatory and antiatherogenic effects. Although the precise mechanism is not yet known, vaccenic acid levels have been inversely correlated with the risk of coronary heart disease in humans $^{52}$. This effect might be mediated by T cells, because male JCR:LA-cp rats fed a diet supplemented with $1.5 \% \mathrm{w} / \mathrm{w}$ vaccenic acid for 3 weeks showed a decreased percentage of $\mathrm{T}_{\mathrm{H}}$ cells in both the spleen and mesenteric lymph nodes compared with rats fed a control diet ( $0 \%$ vaccenic acid) $)^{114}$. In the same study, splenocytes from lean rats fed the vaccenic acid-supplemented diet produced lower concentrations of IL-2, IL-10 and TNF after ex vivo stimulation with the T cell mitogen concanavalin A than splenocytes from lean rats fed the control diet, implying decreased $\mathrm{T}_{\mathrm{H}} 1$ cell and $\mathrm{T}_{\text {reg }}$ cell numbers. By contrast, splenocytes from obese 
rats produced higher IL-10 levels and lower IL-2 and TNF levels after concanavalin A ex vivo stimulation than splenocytes from obese rats fed the control diet. These concentrations were similar to those produced by splenocytes from lean control rats, implying an increase in $\mathrm{T}_{\text {reg }}$ cell numbers and a normalized number of $\mathrm{T}_{\mathrm{H}} 1$ cells $^{114}$. Another study showed that this effect on cytokine levels was mediated by vaccenic acid and not through its conversion to conjugated linoleic acid ${ }^{115}$, which has known anti-inflammatory properties. Human PBMCs exposed in vitro to $11 \mu \mathrm{mol} / 1,33 \mu \mathrm{mol} / 1$ or $100 \mu \mathrm{mol} / 1$ of vaccenic acid for $24 \mathrm{~h}$ had a $>30 \%$ reduction in IL-2 and TNF secretion compared with control cells ${ }^{116}$. Gas chromatography analysis showed that vaccenic acid increased in a dose-dependent manner in the lipid fractions of the cells, but conjugated linoleic acid did not. This finding indicates that vaccenic acid, independent of its conversion to conjugated linoleic acid, induces anti-inflammatory effects in T cells ${ }^{116}$.

PUFAs such as EPA and DHA have distinct anti-inflammatory properties, increasing the proportion and cytokine levels of anti-inflammatory $\mathrm{T}_{\mathrm{H}} 2$ cells and $\mathrm{T}_{\text {reg }}$ cells and decreasing those of pro-inflammatory $\mathrm{T}_{\mathrm{H}} 1$ cells and $\mathrm{T}_{\mathrm{H}} 17$ cells, both in vitro and in vivo in humans and mice ${ }^{100,117-120}$. In one study, NOD mice fed a diet enriched in EPA and DHA for 20 weeks were used in in vivo assays, and in in vitro experiments activated $\mathrm{CD} 4^{+} \mathrm{T}$ cells derived from NOD mice, from four patients with type 1 diabetes mellitus and from five donors without type 1 diabetes were exposed to $50 \mu \mathrm{mol} / \mathrm{l}$ or $100 \mu \mathrm{mol} / \mathrm{l}$ of EPA or DHA for $24 \mathrm{~h}^{112}$. DHA and EPA induced an increase in the number of $\mathrm{T}_{\mathrm{H}} 2$ cells and $\mathrm{T}_{\text {reg }}$ cells and a decrease in the pro-inflammatory subsets $\mathrm{T}_{\mathrm{H}} 1$ and $\mathrm{T}_{\mathrm{H}} 17$. Furthermore, the production of IFN $\gamma$ and IL-17A decreased and of IL- 4 and IL-10 increased ${ }^{112}$. The decrease in total $\mathrm{T}$ cell proliferation and simultaneous upregulation of anti-inflammatory cytokines and subsets and downregulation of pro-inflammatory cytokines and subsets induced by EPA and DHA further indicates that these FAs mediate anti-inflammatory and anti-atherogenic immune responses in T cells.

Determining whether a FA is involved in a pro-inflammatory or anti-inflammatory response is straightforward for some FAs. The PUFAs EPA and DHA show anti-inflammatory, anti-proliferative and anti-atherogenic effects in in vitro and in vivo studies in both human and mouse $\mathrm{T}$ cells ${ }^{112}$. The PUFA arachidonic and the SFA lauric acid both stimulate polarization of pro-inflammatory $\mathrm{T}$ cell subsets and induce proliferation $^{88,112}$. However, not all FAs are as easily classified. Different MUFAs often show contradictory results across different studies that use different concentration or models. For example, the MUFAs palmitoleic acid and oleic acid show both pro-inflammatory and anti-inflammatory effects on $\mathrm{T}$ cell polarization as well as pro-proliferative and anti-proliferative effects ${ }^{90}$. These differences might also be attributed to other characteristics of these FAs, such as chain length and methyl groups. Therefore, whereas the effects of PUFAs and SFAs on $\mathrm{T}$ cell function and atherosclerosis might be easily determined, the role of MUFAs requires further investigation.

\section{Future directions}

Atherosclerosis is a complex disease driven by more than just high cholesterol levels and macrophages. Triglycerides and FAs have an integral role in atherosclerosis development and progression but their mechanisms of action are less well understood. T cells interact with and depend on signals from their environment, of which FAs are particularly important. In this Review, we summarize evidence showing that various FAs can substantially affect $\mathrm{T}$ cell function, which might in turn influence the development and progression of atherosclerosis. The metabolism, activation, proliferation and polarization of $\mathrm{T}$ cells can each be altered by interactions with specific FAs, as summarized in FIG. 1 and TABLE 2.

Nonetheless, many unknowns remain about the complex interactions among FAs, T cells and atherosclerosis. The mechanisms through which FAs influence $\mathrm{T}$ cell functions remain to be elucidated. In this respect, the formation of lipid rafts or metabolite-sensing $\mathrm{G}$ protein-coupled receptors are intriguing areas of research ${ }^{121,122}$. Moreover, whether FA-T cell interactions are similar in the circulation and in atherosclerotic plaques, whether $\mathrm{T}$ cell responses and numbers are related to the FA content in the plaque, and whether FAs can influence $\mathrm{T}$ cell responses to antigens or pathogens have not yet been investigated.

The functional changes in $\mathrm{T}$ cells induced by FAs might also have a role in ameliorating atherosclerosis. This aspect has been widely studied in various studies on pharmacological interventions, especially with the PUFAs, EPA and DHA derived from fish oil, which have been summarized in a meta-analysis and systematic review $^{123}$. One notable study assessing the effects of EPA supplementation on atherosclerosis is the REDUCE-IT trial $^{37,38}$. In this trial, men and women with established CVD who received $2 \mathrm{~g}$ of a highly purified ethyl ester of EPA twice daily had profound reductions in the risk of cardiovascular death compared with participants receiving placebo ${ }^{37,38}$. The trial investigators relate the results to the very high concentrations of purified EPA, to the cell membrane stabilization properties of EPA and a change in high-sensitivity C-reactive protein levels. However, the results were independent of normalizing triglyceride levels in patients, indicating that other mechanisms also affected the outcomes ${ }^{37,38}$. We propose that $\mathrm{T}$ cells might also be a source of the pleiotropic beneficial effects of EPA observed in the REDUCE-IT trial. EPA has been shown to have an anti-inflammatory and suppressive effect on T cells ${ }^{79,91,98-104,112,117-120}$ although this aspect has not yet been studied in relation to the trial outcomes.

SFAs and MUFAs have also been studied in clinical trials on CVD outcomes. The MUFA vaccenic acid has been shown to reduce the risk of CVD in clinical trials, as summarized previously ${ }^{124}$. A meta-analysis of clinical studies investigating the effects of coconut oil, which is rich in the SFA lauric acid, showed that coconut oil intake increases the levels of triglycerides, LDL cholesterol and HDL cholesterol in the plasma compared with intake of other oils ${ }^{89}$. This finding indicates that the consumption of coconut oil, and thereby lauric acid (which makes up around 50\% of the FA component of 
Table 2 | Overview of effects of fatty acids on T cell processes

\begin{tabular}{|c|c|c|c|c|}
\hline \multirow[t]{2}{*}{ Fatty acid } & \multicolumn{4}{|l|}{ T cell process } \\
\hline & Metabolism & Activation & Proliferation & Polarization \\
\hline \multirow[t]{3}{*}{ Lauric acid } & \multirow{3}{*}{$\begin{array}{l}\text { Did not rescue de novo fatty acid } \\
\text { synthesis }^{76}\end{array}$} & \multirow[t]{3}{*}{ NR } & $\uparrow^{88}$ & $\uparrow \mathrm{T}_{H} 1$ cells $^{88}$ \\
\hline & & & Did not rescue $\mathrm{e}^{77}$ & $\uparrow \mathrm{T}_{H} 17$ cells $^{88}$ \\
\hline & & & & $\downarrow T_{\text {reg }}$ cells $^{88}$ \\
\hline Myristic acid & Did not rescue de novo fatty acid synthesis ${ }^{76}$ & NR & Rescued $^{77}$ & NR \\
\hline \multirow[t]{4}{*}{ Palmitic acid } & \multirow[t]{4}{*}{ NR } & \multirow[t]{4}{*}{$\uparrow^{83}$} & $\downarrow^{91}$ & $\uparrow T_{H} 1$ cells $^{88,111}$ \\
\hline & & & $\uparrow^{93}$ & $\uparrow \mathrm{T}_{\mathrm{H}} 17$ cells $^{88,111}$ \\
\hline & & & Rescued $^{77}$ & $\downarrow T_{H} 2$ cells ${ }^{111}$ \\
\hline & & & & $\downarrow T_{\text {reg }}$ cells ${ }^{111}$ \\
\hline \multirow[t]{3}{*}{ Palmitoleic acid } & \multirow[t]{3}{*}{ NR } & \multirow[t]{3}{*}{ NR } & $\downarrow^{90}$ & $\downarrow T_{H} 1$ cells $^{90}$ \\
\hline & & & $\uparrow^{93}$ & $\downarrow T_{H} 17$ cells $^{90}$ \\
\hline & & & Did not rescue $^{77}$ & $\downarrow T_{\text {reg }}$ cells $^{90}$ \\
\hline \multirow[t]{2}{*}{ Stearic acid } & \multirow[t]{2}{*}{ NR } & \multirow[t]{2}{*}{ No effect } & $\downarrow^{93}$ & NR \\
\hline & & & $\uparrow^{91}$ & \\
\hline \multirow[t]{4}{*}{ Oleic acid } & Rescued de novo fatty acid synthesis ${ }^{76}$ & $\uparrow^{84}$ & $\uparrow^{90,92,93}$ & $\downarrow^{90}$ and $\uparrow^{90,111} \mathbf{T}_{H} 1$ cells \\
\hline & \multirow{3}{*}{$\begin{array}{l}\text { Rescued oxidative phosphorylation and } \\
\text { glycolysis }^{77}\end{array}$} & \multirow[t]{3}{*}{ No effect ${ }^{83}$} & Rescued $^{77}$ & $\downarrow^{90}$ and $\uparrow^{111} \mathrm{~T}_{\mathrm{H}} 17$ cells \\
\hline & & & & $\downarrow^{111}$ and $\uparrow^{90} T_{H} 2$ cells \\
\hline & & & & $\downarrow T_{\text {reg }}$ cells $s^{90,111}$ \\
\hline \multirow[t]{3}{*}{ Vaccenic acid } & \multirow[t]{3}{*}{ NR } & \multirow[t]{3}{*}{ NR } & NR & $\downarrow T_{H}$ cells $^{114}$ \\
\hline & & & & $\downarrow T_{H} 1$ cells $^{116}$ \\
\hline & & & & $\uparrow T_{\text {reg }}$ cells $s^{114}$ \\
\hline \multirow[t]{2}{*}{ Linoleic acid } & $\uparrow \beta$-Oxidation ${ }^{78}$ & \multirow[t]{2}{*}{ No effect ${ }^{83}$} & $\uparrow^{93}$ & \multirow[t]{2}{*}{ NR } \\
\hline & $\downarrow$ Electron transport chain respiration ${ }^{78}$ & & Did not rescue ${ }^{77}$ & \\
\hline \multirow[t]{3}{*}{$\gamma$-Linolenic acid } & \multirow[t]{3}{*}{ NR } & \multirow[t]{3}{*}{ No effect ${ }^{83}$} & $\downarrow^{95,96}$ & \multirow[t]{3}{*}{ NR } \\
\hline & & & $\uparrow^{93}$ & \\
\hline & & & Did not rescue ${ }^{77}$ & \\
\hline Arachidic acid & NR & NR & Rescued $^{77}$ & NR \\
\hline Arachidonic acid & NR & No effect ${ }^{83}$ & NR & $\uparrow T_{H} 1$ cells $^{112}$ \\
\hline & & & & $\uparrow \mathrm{T}_{\mathrm{H}} 17$ cells $^{112}$ \\
\hline & & & & $\downarrow T_{H} 2$ cells $^{112}$ \\
\hline Eicosapentaenoic & $\uparrow$ Mitochondrial respiration-associated & NR & $\downarrow^{79,91,98-104}$ & $\downarrow T_{H} 1$ cells $^{112,118-120}$ \\
\hline & & & & $\downarrow T_{H} 17$ cells $^{112,117}$ \\
\hline & & & & $\begin{array}{l}\uparrow^{100,112,118} \text { or no } \\
\text { effect }{ }^{120} \text { on } T_{H} 2 \text { cells }\end{array}$ \\
\hline & & & & $\begin{array}{l}\uparrow^{112} \text { or no effect }{ }^{117} \text { on } \\
\mathrm{T}_{\text {reg }} \text { cells }\end{array}$ \\
\hline $\begin{array}{l}\text { Docosahexaenoic } \\
\text { acid }\end{array}$ & $\begin{array}{l}\text { Did not rescue de novo fatty acid } \\
\text { synthesis }\end{array}$ & $\downarrow^{85}$ & $\downarrow^{79,91,97-104}$ & $\downarrow T_{H} 1$ cells $^{112,118-120}$ \\
\hline & $\begin{array}{l}\uparrow \text { Mitochondrial respiration-associated } \\
\text { proton leakage }^{79}\end{array}$ & & & $\begin{array}{l}\uparrow^{100,112,118} \text { or no } \\
\text { effect }^{120} \text { on } T_{H} 2 \text { cells }\end{array}$ \\
\hline & & & & $\begin{array}{l}\uparrow^{112} \text { or no effect }{ }^{117} \text { on } \\
\mathrm{T}_{\text {reg }} \text { cells }\end{array}$ \\
\hline Lignoceric acid & NR & NR & Did not rescue ${ }^{77}$ & NR \\
\hline
\end{tabular}

$\uparrow$ and $\downarrow$ indicate that the fatty acid had a directed effect on that process. NR, not reported; $T_{H}$ cell, T helper cell; $T_{\text {reg }}$ cell, regulatory $T$ cell.

coconut oil), increases the risk of $\mathrm{CVD}^{89}$. These studies provide overlapping results for the effect of dietary FAs on atherosclerosis and what we describe in this Review about the effect of FAs on T cell function. However, $\mathrm{T}$ cells were not considered in the discussion of these clinical trials. Therefore, establishing and defining the interactions among atherosclerosis, FAs and T cells will be crucial to our understanding of the pathogenesis of this disease and how it can be prevented and treated.

The concentrations of FAs are higher in atherosclerotic plaques than in the circulation and, therefore, the plaque environment might influence effector $\mathrm{T}$ cell functions more strongly ${ }^{125}$. However, if the T cells have already been exposed to high concentrations of FAs, or 


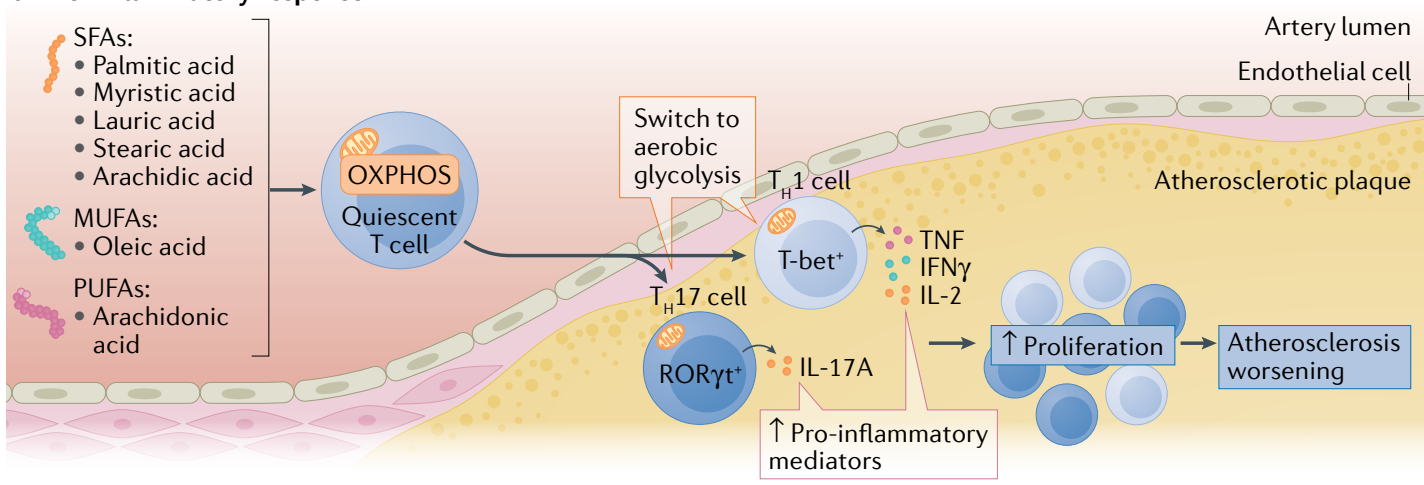

b Anti-inflammatory response

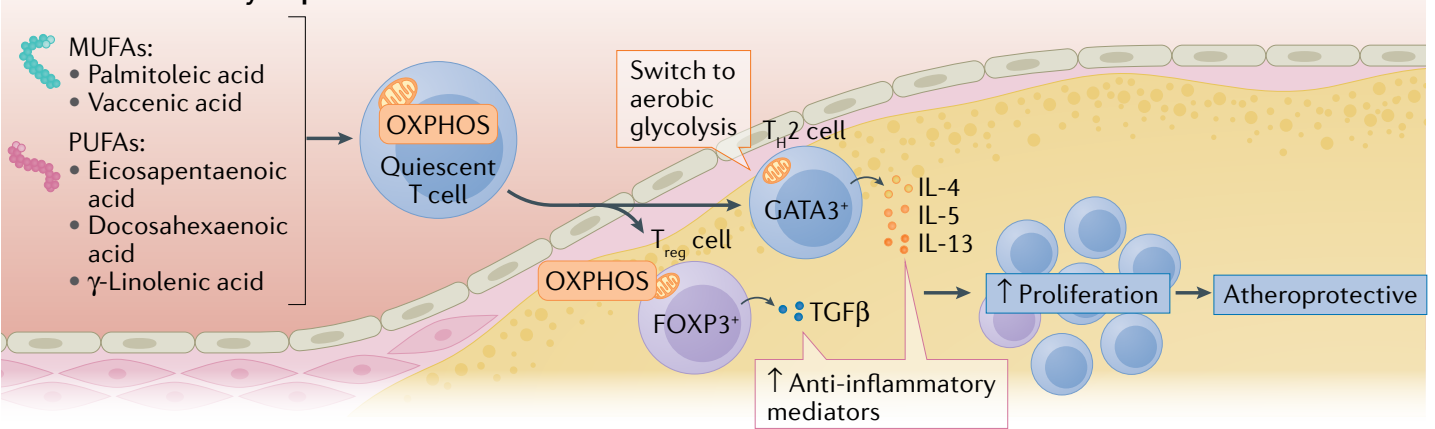

Fig. 2 | Effects of circulating fatty acids on T cell functions in atherosclerosis. Quiescent T cells can take up fatty acids present in the circulation, and the type of fatty acid determines the T cell metabolic switch after the T cell enters the dyslipidaemic environment of the atherosclerotic plaque. The metabolic reprogramming in turn influences the polarization and inflammatory response of the T cell. Saturated fatty acids (SFAs) skew the polarization to pro-inflammatory T helper 1 $\left(T_{H} 1\right)$ cells and $T_{H} 17$ cells, which proliferate and secrete pro-inflammatory cytokines, including interferon- $\gamma$ (IFN $\left.\gamma\right)$, IL-2, tumour necrosis factor (TNF) and IL-17A, thereby contributing to worsening of atherosclerosis (panel a). Monounsaturated fatty acids (MUFAs), such as palmitoleic acid, and polyunsaturated fatty acids (PUFAs), such as docosahexaenoic acid, skew the polarization to anti-inflammatory $T_{H} 2$ cells and regulatory $T\left(T_{\text {reg }}\right)$ cells. The $T_{H} 2$ cells and $T_{\text {reg }}$ cells proliferate and secrete anti-inflammatory cytokines, including IL-4, IL-5, IL-13 and transforming growth factor- $\beta$ (TGF $\beta$ ), that attenuate atherosclerosis (panel b). Of note, the MUFA oleic acid and the PUFA arachidonic acid induce polarization into pro-inflammatory T cell subsets. FOXP3, forkhead box protein P3; GATA3, GATA-binding factor 3; OXPHOS, oxidative phosphorylation; ROR $\gamma$ t, nuclear receptor ROR $\gamma t$; T-bet, T-box transcription factor TBX21.

their precursor triglycerides, in the circulation before migrating into the atherosclerotic plaque, the function of these $\mathrm{T}$ cells has probably already been altered. For example, $\gamma$-linolenic acid has been shown to inhibit $\mathrm{T}$ cell proliferation in vitro when added before $\mathrm{T}$ cell activation ${ }^{96}$. This inhibition is also likely to occur in individuals with hypertriglyceridaemia or obesity and provides a potential link between these conditions and the associated increased risk of developing atherosclerosis ${ }^{126,127}$. More research is needed to identify the precise effects of secondary exposure of the T cells to FAs in atherosclerotic plaques after the T cells have come into contact with FAs in the circulation.

The effects of FAs in altering $\mathrm{T}$ cell metabolism in relation to atherosclerosis development and progression is of particular interest for future investigation. Immunometabolism is highly dependent on FAs, and FAs can influence the $\mathrm{T}$ cell immune response. This rapidly evolving area of research could help explain the changes in $\mathrm{T}$ cell function induced by FAs by providing substantial insight into the mechanisms that drive these changes. The data reviewed here are in accordance with a mechanism involving $\mathrm{T}$ cells undergoing a type of metabolic reprogramming induced by the interactions with FAs in the circulation that might influence the subsequent $\mathrm{T}$ cell effects on diseases such as atherosclerosis.

\section{Conclusions}

We call for a shift in the focus of atherosclerosis research. FAs and triglycerides have re-emerged as crucial mediators in the development of atherosclerosis. Furthermore, atherosclerosis development and progression have also been linked to T cells, with these cells making up $\geq 30 \%$ of the leukocytes present in atherosclerotic plaques in both humans and mice. T cells can be functionally altered by FAs through changes in T cell metabolism. This observation suggests that FAs, T cells and atherosclerosis are linked, and this possible association remains to be further elucidated. We propose that the metabolic reprogramming of $\mathrm{T}$ cells induced by their interactions with FAs in the circulation influences their subsequent functions in disease states such as atherosclerosis (FIG. 2).

Published online: 12 July 2021 
1. Schaftenaar, F., Frodermann, V., Kuiper, J. \& Lutgens, E. Atherosclerosis: the interplay between lipids and immune cells. Curr. Opin. Lipidol. 27 209-215 (2016)

2. Barquera, S. et al. Global overview of the epidemiology of atherosclerotic cardiovascular disease. Arch. Med. Res. 46, 328-338 (2015)

3. Brown, M. S. \& Goldstein, J. L. How LDL receptors influence cholesterol and atherosclerosis. Sci. Am. 251, 58-69 (1984)

4. Brown, M. S. \& Goldstein, J. L. A receptor-mediated pathway for cholesterol homeostasis. Science $\mathbf{2 3 2}$. 34-47 (1986)

5. Tabas, I. \& Lichtman, A. H. Monocyte-macrophages and T cells in atherosclerosis. Immunity 47, 621-634 (2017).

6. Hansson, G. K., Holm, J. \& Jonasson, L. Detection of activated T lymphocytes in the human atherosclerotic plaque. Am. J. Pathol. 135, 169-175 (1989)

7. Jonasson, L., Holm, J., Skalli, O., Bondjers, G. \& Hansson, G. K. Regional accumulations of T cells, macrophages, and smooth muscle cells in the human atherosclerotic plaque. Arteriosclerosis 6, 131-138 (1986).

8. Zhou, X., Nicoletti, A., Elhage, R. \& Hansson, G. K. Transfer of $\mathrm{CD} 4+\mathrm{T}$ cells aggravates atherosclerosis in immunodeficient apolipoprotein $\mathrm{E}$ knockout mice. Circulation 102, 2919-2922 (2000).

9. Zhou, X., Robertson, A. K., Hjerpe, C. \& Hansson, G. K Adoptive transfer of CD4+ T cells reactive to modified low-density lipoprotein aggravates atherosclerosis. Arterioscler. Thromb. Vasc. Biol. 26, 864-870 (2006).

10. Ketelhuth, D. F. \& Hansson, G. K. Adaptive response of $\mathrm{T}$ and $\mathrm{B}$ cells in atherosclerosis. Circ. Res. 118, 668-678 (2016)

11. Aukrust, P. et al. The complex role of T-cell-based immunity in atherosclerosis. Curr. Atheroscler. Rep. 10, 236-243 (2008)

12. Saigusa, R., Winkels, H. \& Ley, K. T cell subsets and functions in atherosclerosis. Nat. Rev. Cardiol. 17 387-401 (2020)

13. Cochain, C. \& Zernecke, A. Protective and pathogenic roles of $\mathrm{CD} 8^{+} \mathrm{T}$ cells in atherosclerosis. Basic Res. Cardiol. 111, 71 (2016)

14. van Duijn, J., Kuiper, J. \& Slutter, B. The many faces of CD8+ T cells in atherosclerosis. Curr. Opin. Lipido 29, 411-416 (2018).

15. van Duijn, J. et al. CD8+ T-cells contribute to lesion stabilization in advanced atherosclerosis by limiting macrophage content and CD4+ T-cell responses. Cardiovasc. Res. 115, 729-738 (2019).

16. Cochain, $C$. et al. CD8+ $T$ cells regulate monopoiesis and circulating Ly6C-high monocyte levels in atherosclerosis in mice. Circ. Res. 117, 244-253 (2015).

17. Leistner, D. M. et al. Differential immunological signature at the culprit site distinguishes acute coronary syndrome with intact from acute coronary syndrome with ruptured fibrous cap: results from the prospective translational OPTICO-ACS study. Eur. Heart J. 41, 3549-3560 (2020)

18. Winkels, $\mathrm{H}$. et al. Atlas of the immune cell repertoire in mouse atherosclerosis defined by single-cell RNA-sequencing and mass cytometry. Circ. Res. 122, 1675-1688 (2018)

19. Fernandez, D. M. et al. Single-cell immune landscape of human atherosclerotic plaques. Nat. Med. 25 , 1576-1588 (2019).

20. Depuydt, M. A. C. et al. Microanatomy of the human atherosclerotic plaque by single-cell transcriptomics. Circ. Res. 127, 1437-1455 (2020)

21. Zernecke, A. et al. Meta-analysis of leukocyte diversity in atherosclerotic mouse aortas. Circ. Res. 127 402-426 (2020)

22. Williams, J. W. et al. Single cell RNA sequencing in atherosclerosis research. Circ. Res. 126, 1112-1126 (2020).

23. Visscher, M. et al. Data processing pipeline for lipid profiling of carotid atherosclerotic plaque with mass spectrometry imaging. J. Am. Soc. Mass. Spectrom. 30, 1790-1800 (2019)

24. Stemme, S. et al. T lymphocytes from human atherosclerotic plaques recognize oxidized low density lipoprotein. Proc. Natl Acad. Sci. USA 92, 3893-3897 (1995)

25. Wolf, D. et al. Pathogenic autoimmunity in atherosclerosis evolves from initially protective apolipoprotein B100-reactive CD4(+) T-regulatory cells. Circulation 142, 1279-1293 (2020).

26. van Puijvelde, G. H. et al. Induction of oral tolerance to oxidized low-density lipoprotein ameliorates atherosclerosis. Circulation 114, 1968-1976 (2006).
27. Klingenberg, R. et al. Intranasal immunization with an apolipoprotein B-100 fusion protein induces antigen-specific regulatory $T$ cells and reduces atherosclerosis. Arterioscler. Thromb. Vasc. Biol. 30 946-952 (2010).

28. Tse, K. et al. Atheroprotective vaccination with MHC-I restricted peptides from ApoB-100. Front. Immunol. 4, 493 (2013)

29. Nilsson, J., Wigren, M. \& Shah, P. K. Regulatory T cells and the control of modified lipoprotein autoimmunitydriven atherosclerosis. Trends Cardiovasc. Med. 19, 272-276 (2009)

30. McNamara, D. J. Dietary cholesterol and atherosclerosis. Biochim. Biophys. Acta 1529 310-320 (2000)

31. Talayero, B. G. $\&$ Sacks, F. M. The role of triglycerides in atherosclerosis. Curr. Cardiol. Rep. 13, 544-552 (2011)

32. Dron, J. S. \& Hegele, R. A. Genetics of triglycerides and the risk of atherosclerosis. Curr. Atheroscler. Rep. 19, 31 (2017)

33. Nordestgaard B G. Triglyceride-rich lipoproteins and atherosclerotic cardiovascular disease new insights from epidemiology, genetics, and biology. Circ. Res. 118, 547-563 (2016).

34. Keech, A. C. \& Jenkins, A. J. Triglyceride-lowering trials. Curr. Opin. Lipidol. 28, 477-487 (2017).

35. Salakhutdinov, N. F. \& Laev, S. S. Triglyceridelowering agents. Bioorg. Med. Chem. 22, 3551-3564 (2014).

36. Budoff, M. Triglycerides and triglyceride-rich lipoproteins in the causal pathway of cardiovascular disease. Am. J. Cardiol. 118, 138-145 (2016).

37. Bhatt, D. L. et al. Cardiovascular risk reduction with icosapent ethyl for hypertriglyceridemia. N. Engl. J. Med. 380, 11-22 (2019)

38. Bhatt, D. L. et al. Effects of icosapent ethyl on total ischemic events from REDUCE-IT. J. Am. Coll. Cardiol. 73, 2791-2802 (2019).

39. Kersten, S. Triglyceride metabolism under attack. Cell Metab. 25, 1209-1210 (2017)

40. Kersten, S. Physiological regulation of lipoprotein lipase. Biochim. Biophys. Acta 1841, 919-933 (2014).

41. Ding, D. et al. Association between erythrocyte membrane $n-3$ and $n-6$ polyunsaturated fatty acids and carotid atherosclerosis: a prospective study. Atherosclerosis 298, 7-13 (2020)

42. Steffen, B. T., Duprez, D., Szklo, M., Guan, W. $\delta$ Tsai, M. Y. Circulating oleic acid levels are related to greater risks of cardiovascular events and all-cause mortality: The Multi-Ethnic Study of Atherosclerosis. J. Clin. Lipidol. 12, 1404-1412 (2018).

43. Afonso, M. S. et al. Dietary interesterified fat enriched with palmitic acid induces atherosclerosis by impairing macrophage cholesterol efflux and eliciting inflammation. J. Nutr. Biochem. 32, 91-100 (2016).

44. Marangoni, F. et al. Dietary linoleic acid and human health: focus on cardiovascular and cardiometabolic effects. Atherosclerosis 292, 90-98 (2020).

45. Yang, Z. H. et al. Dietary palmitoleic acid attenuates atherosclerosis progression and hyperlipidemia in low-density lipoprotein receptor-deficient mice. Mol. Nutr. Food Res. 63, 1900120 (2019).

46. Gallagher, H. et al. Dihomo- $\gamma$-linolenic acid inhibits several key cellular processes associated with atherosclerosis. Biochim. Biophys. Acta Mol. Basis Dis. 1865, 2538-2550 (2019)

47. Noto, D. et al. Myristic acid is associated to low plasma HDL cholesterol levels in a Mediterranean population and increases HDL catabolism by enhancing HDL particles trapping to cell surface proteoglycans in a liver hepatoma cell model. Atherosclerosis 246, 50-56 (2016).

48. Yamagishi, K., Nettleton, J. A., Folsom, A. R. \& Investigators, A. S. Plasma fatty acid composition and incident heart failure in middle-aged adults: the Atherosclerosis Risk in Communities (ARIC) Study. Am. Heart J. 156, 965-974 (2008).

49. Valenzuela, C. A., Baker, E. J., Miles, E. A. \& Calder, P. C. Eighteen-carbon trans fatty acids and inflammation in the context of atherosclerosis. Prog. Lipid Res. 76, 101009 (2019)

50. Delgado, G. E. et al. Individual omega- 9 monounsaturated fatty acids and mortality - the Ludwigshafen Risk and Cardiovascular Health Study. J. Clin. Lipidol. 11, 126-135 (2017).

51. Liu, L. et al. Protective role of n6/n3 PUFA supplementation with varying DHA/EPA ratios against atherosclerosis in mice. J. Nutr. Biochem. 32 , $171-180(2016)$
52. Djousse, L., Matthan, N. R., Lichtenstein, A. H. ¿ Gaziano, J. M. Red blood cell membran concentration of cis-palmitoleic and cis-vaccenic acids and risk of coronary heart disease. Am. J. Cardiol. 110, 539-544 (2012).

53. Spigoni, V. et al. Stearic acid at physiologic concentrations induces in vitro lipotoxicity in circulating angiogenic cells. Atherosclerosis $\mathbf{2 6 5}$ 162-171 (2017)

54. Kelley, D. S. \& Adkins, Y. Similarities and differences between the effects of EPA and DHA on markers of atherosclerosis in human subjects. Proc. Nutr. Soc. 71 322-331 (2012)

55. Mensink, R. P., Zock, P. L., Kester, A. D. M. \& Katan, M. B. Effects of dietary fatty acids and carbohydrates on the ratio of serum total to HDL cholesterol and on serum lipids and apolipoproteins: a meta-analysis of 60 controlled trials. Am. J. Clin. Nutr. 77, 1146-1155 (2003)

56. Polonskaya, Y. V. et al. Balance of fatty acids and their correlations with parameters of lipid metabolism and markers of inflammation in men with coronary atherosclerosis. Bull. Exp. Biol. Med. 164, 33-35 (2017).

57. Chung, H. K. et al. Plasma phospholipid arachidonic acid and lignoceric acid are associated with the risk of cardioembolic stroke. Nutr. Res. 35, 1001-1008 (2015).

58. Ghoshal, S., Witta, J., Zhong, J., de Villiers, W. $\&$ Eckhardt, E. Chylomicrons promote intestina absorption of lipopolysaccharides. J. Lipid Res. 50, 90-97 (2009)

59. Randolph, G. J. \& Miller, N. E. Lymphatic transport of high-density lipoproteins and chylomicrons. J. Clin. Invest. 124, 929-935 (2014).

60. Ratnayake, W. M. \& Galli, C. Fat and fatty acid terminology, methods of analysis and fat digestion and metabolism: a background review paper. Ann. Nutr. Metab. 55, 8-43 (2009).

61. Chowdhury, R. et al. Association of dietary, circulating, and supplement fatty acids with coronary risk. Ann. Intern. Med. 160, 398-406 (2014).

62. Spady, K. D., Woollett, L. A. \& Dietschy, J. M. Regulation of plasma LDL-cholesterol levels by dietary cholesterol and fatty acids. Annu. Rev. Nutr. 13, 355-381 (1993)

63. Chapman, N. M., Boothby, M. R. \& Chi, H. Metabolic coordination of $\mathrm{T}$ cell quiescence and activation. Nat. Rev. Immunol. 20, 55-70 (2020).

64. Sprent, J. \& Surh, C. D. Normal T cell homeostasis: the conversion of naive cells into memory-phenotype cells. Nat. Immunol. 12, 478-484 (2011).

65. Smith-Garvin, J. E., Koretzky, G. A. \& Jordan, M. S. T cell activation. Annu. Rev. Immunol. 27, 591-619 (2009).

66. Guermonprez, P., Valladeau, J., Zitvogel, L., Thery, C. $\&$ Amigorena, S. Antigen presentation and T cell stimulation by dendritic cells. Annu. Rev. Immunol. 20 621-667 (2002).

67. Geissmann, F. et al. Blood monocytes: distinct subsets, how they relate to dendritic cells, and their possible roles in the regulation of T-cell responses. Immunol. Cell Biol. 86, 398-408 (2008).

68. Ramsay, G. \& Cantrell, D. Environmental and metabolic sensors that control T cell biology. Front. Immunol. 6, 99 (2015).

69. Koltsova, E. K. et al. Dynamic T cell-APC interactions sustain chronic inflammation in atherosclerosis. J. Clin. Investig. 122, 3114-3126 (2012).

70. Geltink, R. I. K., Kyle, R. L. \& Pearce, E. L. Unraveling the complex interplay between $T$ cell metabolism and function. Annu. Rev. Immunol. 36, 461-488 (2018).

71. Howie, D., Ten Bokum, A., Necula, A. S., Cobbold, S. P. $\&$ Waldmann, H. The role of lipid metabolism in T lymphocyte differentiation and survival. Front. Immunol. 8, 1949 (2017).

72. Kopf, H., de la Rosa, G. M., Howard, O. M. \& Chen, X. Rapamycin inhibits differentiation of Th 17 cells and promotes generation of FoxP3+ T regulatory cells. Int. Immunopharmacol. 7, 1819-1824 (2007).

73. Young, K. E., Flaherty, S., Woodman, K. M., Sharma-Walia, N. \& Reynolds, J. M. Fatty acid synthase regulates the pathogenicity of Th17 cells. J. Leukoc. Biol. 102, 1229-1235 (2017).

74. Berod, L. et al. De novo fatty acid synthesis controls the fate between regulatory $\mathrm{T}$ and $\mathrm{T}$ helper 17 cells. Nat. Med. 20, 1327-1333 (2014)

75. O'Sullivan, D. \& Pearce, E. L. Fatty acid synthesis tips the TH17-Treg cell balance. Nat. Med. 20, 1235-1236 (2014). 
76. Endo, Y. et al. Obesity drives Th 17 cell differentiation by inducing the lipid metabolic kinase, ACC1. Cell Rep. 12, 1042-1055 (2015)

77. Angela, M. et al. Fatty acid metabolic reprogramming via mTOR-mediated inductions of PPAR $\gamma$ directs early activation of T cells. Nat. Commun. 7, 13683 (2016).

78. Ma, C. et al. NAFLD causes selective CD4+ T lymphocyte loss and promotes hepatocarcinogenesis. Nature 531, 253-257 (2016).

79. Fan, Y. Y. et al. Remodelling of primary human CD4+ T cell plasma membrane order by $n-3$ PUFA. Br. J. Nutr. 119, 163-175 (2018).

80. Borow, K. M., Nelson, J. R. \& Mason, R. P. Biologic plausibility, cellular effects, and molecular mechanisms of eicosapentaenoic acid (EPA) in atherosclerosis. Atherosclerosis 242, 357-366 (2015).

81. Stegemann, C. et al. Comparative lipidomics profiling of human atherosclerotic plaques. Circ. Cardiovasc. Genet. 4, 232-242 (2011)

82. Cochran, J. R., Cameron, T. O. \& Stern, L. J. The relationship of MHC-peptide binding and $\mathrm{T}$ cell activation probed using chemically defined $\mathrm{MHC}$ class II oligomers. Immunity 12, 241-250 (2000)

83. Stentz, F. B. \& Kitabchi, A. E. Palmitic acid-induced activation of human T-lymphocytes and aortic endothelial cells with production of insulin receptors, reactive oxygen species, cytokines, and lipid peroxidation. Biochem. Biophys. Res. Commun. 346, 721-726 (2006)

84. Moussa, M. et al. In vivo effects of olive oil-based lipid emulsion on lymphocyte activation in rats. Clin. Nutr. 19, 49-54 (2000).

85. Kew, S. et al. Effects of oils rich in eicosapentaenoic and docosahexaenoic acids on immune cell composition and function in healthy humans. Am. J. Clin. Nutr. 79, 674-681 (2004).

86. Steffen, B. T. et al. Plasma n-3 and n-6 fatty acids are differentially related to carotid plaque and its progression: the multi-ethnic study of atherosclerosis. Arterioscler. Thromb. Vasc. Biol. 38, 653-659 (2018).

87. Shipkova, M. \& Wieland, E. Surface markers of lymphocyte activation and markers of cell proliferation. Clin. Chim. Acta 413, 1338-1349 (2012).

88. Haghikia, A. et al. Dietary fatty acids directly impact central nervous system autoimmunity via the small intestine. Immunity 43, 817-829 (2015).

89. Jayawardena, R., Swarnamali, H., Lanerolle, P. \& Ranasinghe, P. Effect of coconut oil on cardio-metabolic risk: a systematic review and meta-analysis of interventional studies. Diabetes Metab. Syndr. 14 2007-2020 (2020)

90. Passos, M. E. et al. Differential effects of palmitoleic acid on human lymphocyte proliferation and function. Lipids Health Dis. 15, 217 (2016).

91. Gorjao, R., Cury-Boaventura, M. F., de Lima, T. M. \& Curi, R. Regulation of human lymphocyte proliferation by fatty acids. Cell Biochem. Funct. 25, 305-315 (2007).

92. Miura, S. et al. Increased proliferative response of lymphocytes from intestinal lymph during long chain fatty acid absorption. Immunology 78, 142-146 (1993).

93. Ioan-Facsinay, A. et al. Adipocyte-derived lipids modulate CD4+ T-cell function. Eur. J. Immunol. 43 1578-1587 (2013).

94. Wang, L., Folsom, A. R. \& Eckfeldt, J. H. Plasma fatty acid composition and incidence of coronary heart disease in middle aged adults: the Atherosclerosis Risk in Communities (ARIC) study. Nutr. Metab. Cardiovasc. Dis. 13, 256-266 (2003).

95. Rossetti, R. G., Seiler, C. M., DeLuca, P., Laposata, M. $\S$ Zurier, R. B. Oral administration of unsaturated fatty acids: effects on human peripheral blood T lymphocyte proliferation. J. Leukoc. Biol. 62, 438-443 (1997).

96. Zurier, R. B., Rossetti, R. G., Seller, C. M. \& Laposata, M. Human peripheral blood T lymphocyte proliferation after activation of the T cell receptor: effects of unsaturated fatty acids. Prostaglandins Leukot Essent. Fatty Acids 60, 371-375 (1999).

97. Fan, Y. Y., Ly, L. H., Barhoumi, R., McMurray, D. N ¿ Chapkin, R. S. Dietary docosahexaenoic acid suppresses $\mathrm{T}$ cell protein kinase $\mathrm{C} \theta$ lipid raft recruitment and IL-2 production. J. Immunol. 173, 6151-6160 (2004)

98. Pompos, L. J. \& Fritsche, K. L. Antigen-driven murine CD4+ T lymphocyte proliferation and interleukin-2 production are diminished by dietary (n-3) polyunsaturated fatty acids. J. Nutr. 132, 3293-3300 (2002).
99. Ly, L. H., Smith, R., Switzer, K. C., Chapkin, R. S \& McMurray, D. N. Dietary eicosapentaenoic acid modulates CTLA-4 expression in murine $\mathrm{CD4} 4^{+} \mathrm{T}$-cells. Prostaglandins Leukot. Essent. Fatty Acids 74, 29-37 (2006).

100. Merzouk, S. A. et al. N-3 polyunsaturated fatty acids modulate in-vitro T cell function in type I diabetic patients. Lipids 43, 485-497 (2008).

101. Jolly, C. A., Jiang, Y., Chapkin, R. S. \& McMurray, D. N Dietary $(n-3)$ polyunsaturated fatty acids suppress murine lymphoproliferation, interleukin-2 secretion, and the formation of diacylglycerol and ceramide. J. Nutr. 127, 37-43 (1997).

102. Collison, L. W., Collison, R. E., Murphy, E. J. $\varnothing$ Jolly, C. A. Dietary n-3 polyunsaturated fatty acids increase T-lymphocyte phospholipid mass and acyl-CoA binding protein expression. Lipids 40, 81-87 (2005).

103. McMurray, D. N., Jolly, C. A. \& Chapkin, R. S Effects of dietary $n-3$ fatty acids on T cell activation and $\mathrm{T}$ cell receptor-mediated signaling in a murine model. J. Infect. Dis. 182, S103-S107 (2000).

104. Thies, F. et al. Dietary supplementation with $\gamma$-linolenic acid or fish oil decreases T lymphocyte proliferation in healthy older humans. J. Nutr. 131, 1918-1927 (2001).

105. Ding, L. et al. Eicosapentaenoic acid-enriched phospholipids improve atherosclerosis by mediating cholesterol metabolism. J. Funct. Foods 32, 90-97 (2017).

106. Erkkila, A. T., Matthan, N. R., Herrington, D. M. \& Lichtenstein, A. H. Higher plasma docosahexaenoic acid is associated with reduced progression of coronary atherosclerosis in women with CAD. J. Lipid Res. 47, 2814-2819 (2006)

107. Van Noolen, L. et al. Docosahexaenoic acid supplementation modifies fatty acid incorporation in tissues and prevents hypoxia induced-atherosclerosis progression in apolipoprotein-E deficient mice. Prostaglandins Leukot. Essent. Fatty Acids 91, 111-117 (2014)

108. de Oliveira Otto, M. C. et al. Circulating and dietary omega- 3 and omega- 6 polyunsaturated fatty acids and incidence of CVD in the multi-ethnic study of atherosclerosis. J. Am. Heart Assoc. 2, 000506 (2013).

109. Chang, C. L. \& Deckelbaum, R. J. Omega-3 fatty acids: mechanisms underlying "protective effects" in atherosclerosis. Curr. Opin. Lipidol. 24, 345-350 (2013).

110. Block, R. C., Harris, W. S., Reid, K. J., Sands, S. A. \& Spertus, J. A. EPA and DHA in blood cell membranes from acute coronary syndrome patients and controls. Atherosclerosis 197, 821-828 (2008).

111. Hossein zade, A. Fatty acids effect on T helper differentiation in vitro. Int. J. Food Sci. Nutr. 5, 372-377 (2016)

112. $\mathrm{Bi}, \mathrm{X}$. et al. $\omega-3$ polyunsaturated fatty acids ameliorate type 1 diabetes and autoimmunity. J. Clin. Invest. 127, 1757-1771 (2017)

113. Raphael, I., Nalawade, S., Eagar, T. N. \& Forsthuber, T. G. $\mathrm{T}$ cell subsets and their signature cytokines in autoimmune and inflammatory diseases. Cytokine 74, 5-17 (2015)

114. Blewett, H. J., Gerdung, C. A., Ruth, M. R., Proctor, S. D. $\&$ Field, C. J. Vaccenic acid favourably alters immune function in obese JCR:LA-cp rats. Br. J. Nutr. 102 526-536 (2009)

115. Reynolds, C. M. \& Roche, H. M. Conjugated linoleic acid and inflammatory cell signalling. Prostaglandin Leukot. Essent. Fatty Acids 82, 199-204 (2010).

116. Jaudszus, A. et al. Vaccenic acid-mediated reduction in cytokine production is independent of c9,t11-CLA in human peripheral blood mononuclear cells. Biochim. Biophys. Acta 1821, 1316-1322 (2012).

117. Monk, J. M., Hou, T. Y., Turk, H. F., McMurray, D. N. \& Chapkin, R. S. n3 PUFAs reduce mouse CD4+ T-cell ex vivo polarization into Th 17 cells. J. Nutr. 143, 1501-1508 (2013)

118. Zhang, P., Smith, R., Chapkin, R. S. \& McMurray, D. N. Dietary (n-3) polyunsaturated fatty acids modulate murine Th1/Th2 balance toward the Th2 pole by suppression of Th 1 development. J. Nutr 135 1745-1751 (2005).

119. Zhang, P. et al. Dietary fish oil inhibits antigenspecific murine Th1 cell development by suppression of clonal expansion. J. Nutr. 136, 2391-2398 (2006).

120. Switzer, K. C., McMurray, D. N., Morris, J. S. \& Chapkin, R. S. (n-3) Polyunsaturated fatty acids promote activation-induced cell death in murin T lymphocytes. J. Nutr. 133, 496-503 (2003).
121. Robinson, G. A., Waddington, K. E., Pineda-Torra, I. \& Jury, E. C. Transcriptional regulation of T-cell lipid metabolism: implications for plasma membrane lipid rafts and T-cell function. Front. Immunol. 8 1636 (2017).

122. Tan, J. K., McKenzie, C., Marino, E., Macia, L. \& Mackay, C. R. Metabolite-sensing $G$ protein-coupled receptors-facilitators of diet-related immune regulation. Annu. Rev. Immunol. 35, 371-402 (2017)

123. Wu, G. et al. The efficacy of fish oil in preventing coronary heart disease: A systematic review and meta-analysis. Preprints https://doi.org/10.20944/ preprints202009.0497.v1 (2020).

124. Wang, Y., Jacome-Sosa, M. M., Vine, D. F. \& Proctor, S. D. Beneficial effects of vaccenic acid on postprandial lipid metabolism and dyslipidemia: impact of natural trans-fats to improve CVD risk. Lipid Technol. 22, 103-106 (2010).

125. Pettinella, C., Lee, S. H., Cipollone, F. \& Blair, I. A Targeted quantitative analysis of fatty acids in atherosclerotic plaques by high sensitivity liquid chromatography/tandem mass spectrometry. J. Chromatogr. B 850, 168-176 (2007).

126. Rocha, V. Z. \& Libby, P. Obesity, inflammation, and atherosclerosis. Nat. Rev. Cardiol. 6, 399-409 (2009).

127. Peng, J., Luo, F., Ruan, G., Peng, R. \& Li, X Hypertriglyceridemia and atherosclerosis. Lipids Health Dis. 16, 233 (2017).

128. Bicalho, B., David, F., Rumplel, K., Kindt, E. \& Sandra, P. Creating a fatty acid methyl ester database for lipid profiling in a single drop of human blood using high resolution capillary gas chromatography and mass spectrometry. J. Chromatogr. A 1211, 120-128 (2008).

129. Maecker, H. T., McCoy, J. P. \& Nussenblatt, R. Standardizing immunophenotyping for the Human Immunology Project. Nat. Rev. Immunol. 12 191-200 (2012)

130. McLaughlin, B. E. et al. Nine-color flow cytometry for accurate measurement of $\mathrm{T}$ cell subsets and cytokine responses. Part I: panel design by an empiric approach. Cytometry A 73A, 400-410 (2008).

131. Leng, S. X. et al. ELISA and multiplex technologies for cytokine measurement in inflammation and aging research. J. Gerontol. A Biol. Sci. Med. Sci. 63 879-884 (2008)

132. Zhou, L., Chong, M. M. \& Littman, D. R. Plasticity of CD4+ T cell lineage differentiation. Immunity 30 646-655 (2009).

133. Zhu, J., Yamane, H. \& Paul, W. E. Differentiation of effector CD4 T cell populations*. Annu. Rev. Immunol. 28, 445-489 (2010)

134. Szabo, S. J., Sullivan, B. M., Peng, S. L. \& Glimcher, L. H. Molecular mechanisms regulating Th1 immune responses. Annu. Rev. Immunol. 21, 713-758 (2003).

135. Sandquist, I. \& Kolls, J. Update on regulation and effector functions of Th 17 cells. F1000 Res. 7, 205 (2018).

136. Nakayama, T et al. Th2 cells in health and disease. Annu. Rev. Immunol. 35, 53-84 (2017).

137. Foks, A. C., Lichtman, A. H. \& Kuiper, J. Treating atherosclerosis with regulatory T cells. Arterioscler. Thromb. Vasc. Biol. 35, 280-287 (2015)

138. Seumois, G. et al. Transcriptional profiling of Th2 cells identifies pathogenic features associated with asthma. J. Immunol. 197, 655-664 (2016).

139. Fournier, C. \& Where, Do. T. Cells stand in rheumatoid arthritis? Jt. Bone Spine 72, 527-532 (2005).

140. Roep, B. O. The role of T-cells in the pathogenesis of type 1 diabetes: from cause to cure. Diabetologia $\mathbf{4 6}$ 305-321 (2003).

141. Maclver, N. J., Michalek, R. D. \& Rathmell, J. C. Metabolic regulation of T lymphocytes. Annu. Rev. Immunol. 31, 259-283 (2013).

142. Vander Heiden, M. G., Cantley, L. C. \& Thompson, C. B. Understanding the Warburg effect: the metabolic requirements of cell proliferation. Science 324 1029-1033 (2009).

143. Warburg, O., Gawehn, K. \& Geissler, A. W. Metabolism of leukocytes [German]. Z. Naturforsch. B 13B, 515-516 (1958)

144. Michalek, R. D. et al. Cutting edge: distinct glycolytic and lipid oxidative metabolic programs are essential for effector and regulatory CD4+ T cell subsets. J. Immunol. 186, 3299-3303 (2011).

145. Cluxton, D., Petrasca, A., Moran, B. \& Fletcher, J. M. Differential regulation of human Treg and Th1 7 cells by fatty acid synthesis and glycolysis. Front. Immunol. 10, 115 (2019). 
146. Fullerton, M. D., Steinberg, G. R. \& Schertzer, J. D. Immunometabolism of AMPK in insulin resistance and atherosclerosis. Mol. Cell. Endocrinol. 366, 224-234 (2013).

147. Maganto-Garcia, E., Tarrio, M. L., Grabie, N., Bu, D. X. \& Lichtman, A. H. Dynamic changes in regulatory $T$ cells are linked to levels of diet-induced hypercholesterolemia. Circulation 124, 185-195 (2011).

148. Ketelhuth, D. F. J. et al. Immunometabolism and atherosclerosis: perspectives and clinical significance: a position paper from the Working Group on Atherosclerosis and Vascular Biology of the European Society of Cardiology. Cardiovasc. Res. 115, 1385-1392 (2019).

149. Gistera, A. \& Ketelhuth, D. F. J. Lipid-driven immunometabolic responses in atherosclerosis. Curr. Opin. Lipidol. 29, 375-380 (2018).

150. Tomas, L. et al. Altered metabolism distinguishes high-risk from stable carotid atherosclerotic plaques. Eur. Heart J. 39, 2301-2310 (2018).

151. Amersfoort, J. et al. Diet-induced dyslipidemia induces metabolic and migratory adaptations in regulatory T cells. Cardiovasc. Res. 117, 1309-1324 (2021)

152. Delgoffe, G. M. et al. mTOR differentially regulates effector and regulatory $\mathrm{T}$ cell lineage commitment. Immunity 30, 832-844 (2009).
153. Delgoffe, G. M. et al. The kinase mTOR regulates the differentiation of helper T cells through the selective activation of signaling by mTORC 1 and $\mathrm{mTORC} 2$. activation of signaling by mTORC1 and
Nat. Immunol. 12, 295-303 (2011).

154. Shi, L. Z. et al. HIF1a-dependent glycolytic pathway orchestrates a metabolic checkpoint for the differentiation of TH1 7 and Treg cells. J. Exp. Med. 208, 1367-1376 (2011).

Acknowledgements

The authors' work is supported by the Netherlands CardioVascular Research Initiative (The Dutch Heart Foundation, Dutch Federation of University Medical Centres, the Netherlands Organization for Health Research and Development, and the Royal Netherlands Academy of Sciences) for the GENIUSII project Generating the Best Evidence-Based Pharmaceutical Targets for Atherosclerosis (CVON2011-19, CVON2017-20) and the Joint Programming Initiative a Healthy Diet for a Healthy Life (JPI HDHL) administered by ZonMW, the Netherlands (grant 529051021).

\section{Author contributions}

N.A.R. researched data for the article and wrote the manuscript. B.T.H. and J.W.J. conceived and designed the content of the manuscript. All the authors provided substantial contributions to the discussion of content and reviewed and edited the manuscript before submission.
Competing interests

The authors declare no competing interests.

Peer review information

Nature Reviews Cardiology thanks the anonymous reviewers

for their contribution to the peer review of this work.

\section{Publisher's note}

Springer Nature remains neutral with regard to jurisdictional claims in published maps and institutional affiliations.

\section{Review criteria}

We conducted a literature search divided into three main strategies. First, we searched for the four T cell responses, metabolism, activation, proliferation and polarization, together with different fatty acid names. Second, we searched for the four $T$ cell responses in combination with the term "atherosclerosis". Third, we searched fatty acid names in combination with the term "atherosclerosis". The different T cell subsets (CD8 $C D 4^{+}, T_{H} 1, T_{H} 2, T_{H} 17$ and $T_{\text {reg }}$ cells) were also used as search terms in combination with the groups listed above.

\section{Supplementary information}

The online version contains supplementary material available at https://doi.org/10.1038/s41569-021-00582-9.

(c) Springer Nature Limited 2021 